\title{
The effect of linguistic nativeness in structural priming in comprehension
}

Article

Accepted Version

Nitschke, S., Serratrice, L. and Kidd, E. (2014) The effect of linguistic nativeness in structural priming in comprehension. Language, Cognition and Neuroscience, 29 (5). pp. 525-542. ISSN 2327-3801 doi:

https://doi.org/10.1080/01690965.2013.766355 Available at https://centaur.reading.ac.uk/67095/

It is advisable to refer to the publisher's version if you intend to cite from the work. See Guidance on citing.

To link to this article DOI: http://dx.doi.org/10.1080/01690965.2013.766355

Publisher: Taylor \& Francis

All outputs in CentAUR are protected by Intellectual Property Rights law, including copyright law. Copyright and IPR is retained by the creators or other copyright holders. Terms and conditions for use of this material are defined in the End User Agreement.

\section{www.reading.ac.uk/centaur}

\section{CentAUR}

Central Archive at the University of Reading 
Reading's research outputs online 
The effect of linguistic nativeness on structural priming in comprehension.

Sanjo Nitschke, Ludovica Serratrice \& Evan Kidd

The University of Manchester

\section{Address for correspondence:}

Sanjo Nitschke

School of Psychological Sciences

The University of Manchester

Oxford Road M13 9PL

Email: sanjo.nitschke@gmail.com

Word count excluding abstract, references and appendix: 13363

Word count including abstract, references and appendix: $\mathrm{XXXXX}$ 


\begin{abstract}
The role of linguistic experience in structural priming is unclear. Although it is explicitly predicted that experience contributes to priming effects on at least one theoretical account (Chang, Dell, \& Bock, 2006), to date the empirical data has been mixed. To investigate this issue we conducted four sentence-picture matching experiments that primed for the comprehension of object relative clauses in L1 and proficient L2 speakers of German. It was predicted that an effect of experience would only be observed in instances where priming effects are likely to be weak in experienced L1 speakers. In such circumstances priming should still be strong in L2 speakers because of their comparative lack of experience using and processing the L2 test structures. The experiments therefore systematically manipulated the primes to decrease lexical and conceptual overlap between primes and targets. The results supported the hypothesis: in two of the four studies the L2 group showed different priming effects when compared to the L1 group. This effect only occurred when animacy differences were introduced between the prime and target. The results suggest that linguistic experience as operationalised by nativeness affects the strength of priming, specifically in cases where there is a lack of lexical and conceptual overlap between prime and target. .
\end{abstract}


The effect of linguistic nativesness in structural priming in comprehension Structural priming refers to the persistent use of syntactic structures or interpretative strategies following their use in recent discourse. For example, speakers are more likely to produce a passive such as The girl was kissed by the boy after encountering another passive than after encountering an active, such as The boy kissed the girl (Bock, 1986). Priming of interpretations can be found in the case of ambiguous expressions. For instance, Branigan, Pickering and McLean (2005) primed comprehension of sentences that contained ambiguity of prepositional phrase (PP) attachment, such as The clown prodding the doctor with the banana. They showed that participants were more likely to attach the ambiguous PP to the verb phrase (VP) after previous exposure to a prime sentence that disambiguated a similar sentence in the same manner, as opposed to attaching the PP to the second noun phrase (i.e., the doctor).

Structural priming has been attributed to residual activation of the syntactic structures (Pickering \& Branigan, 1998), but has also been explained as implicit learning (Bock \& Griffin, 2000; Chang, Dell, Bock \& Griffin, 2000). While the former readily explains short-term effects of priming that appear after the exposure to single primes, the latter accounts for priming effects that persist over intervening items that may also accumulate with the increasing number of primes of the same type. Activation is supported by the finding that open-class lexical overlap between primes and targets enhances the effect of priming (Branigan, et al., 2005; Pickering \& Branigan, 1998) and by the observation that the retrieval of specific (Logan, 1985) or semantically related words can be facilitated through structural priming (Nicol \& Pickering, 1993). Strong evidence for implicit learning comes from the finding that priming can last over various filler items, even in the absence of open-class lexical overlap (Bock, Dell, Chang \& Onishi, 2007; Bock \& Griffin, 2000). Additionally, Ferreira, Bock, Wilson, \& Cohen (2008) reported priming in patients with anterograde amnesia. Since these patients have compromised explicit memory yet intact implicit learning abilities, the data argue persuasively for an implicit learning explanation. Finally, Kidd (in press) reported that performance on an implicit learning task was directly associated with long-term structural priming in 5-year-old children, whereas explicit learning was not. Since evidence has been reported in support of both the 
activation and implicit learning accounts, newer proposals suggest that activation and learning are complementary facets of structural priming (Branigan, 2006; Ferreira \& Bock, 2006; Pickering \& Ferreira, 2008).

If structural priming is a form of learning than it may be a crucial force in language acquisition. As such, comparing linguistic groups who differ in their experience can contribute to the debate regarding the circumstances under which priming is likely to result from activation versus learning. More generally, such comparisons can shed light on the language learning process itself, as well as inform pedagogical practice. Whereas the conditions that lead to priming in language production are well documented, there has been comparatively less research investigating priming in language comprehension. Furthermore, little research has been carried out that compares priming in L1 and L2 speakers (but see Bernolet, Hartsuiker \& Pickering, 2007; Bernolet, Hartsuiker \& Pickering, 2009; Hartsuiker, Pickering \& Veltkamp, 2004; McDonough, 2006; Nitschke, Kidd \& Serratrice, 2010; Schoonbaert, Hartsuiker \& Pickering, 2007). The present research investigates priming through comprehension in L1 and L2 speakers of German.

Most studies that have reported L2 priming have primed across languages, from the $L 1$ to the $L 2$, and have primed production. For instance, Hartsuiker et al. (2004) used the confederate scripting technique (see Branigan, Pickering \& Cleland, 2000a) to prime actives and passives from Spanish to English. They found that L1 Spanish participants who spoke L2 English were more likely to use a Spanish passive to describe a picture after hearing a confederate using an English passive description than after hearing an English active description. Salamoura and Williams (2007) reported priming of double object (DO, The boy handing the girl a flower) and prepositional object (PO, The boy handing a flower to the girl) datives from Greek to English. They found that L1 Greek speakers of L2 English were more likely to use a DO dative to complete an ambiguous sentence fragment in English after completing a sentence fragment in Greek that only allowed a DO completion. Similarly, the likelihood of using a PO dative in the English targets increased if the Greek prime fragment only allowed a PO completion. In a similar experiment, Salamoura and Williams (2006) primed English PO and DO dative constructions by using single Dutch words that were only compatible with either a PO or a DO dative construction. 
The likelihood with which participants used a DO or a PO dative to complete an English sentence fragment depended on whether the previously presented Dutch verb could be used exclusively with a DO or a PO dative structure. Finally, Loebell and Bock (2003) found priming of PO and DO dative constructions from listening to spoken production between L1 German and L2 English in both directions (i.e. L1 to L2 and L2 to L1), and Bernolet et al. (2009) successfully primed the use of active and passive constructions from L1 Dutch to L2 English.

The findings from the cross-language priming studies suggest that the different languages spoken by multilingual individuals have shared representations and processing mechanisms. However, cross-language priming studies are limited in their capacity to investigate whether nativeness (and therefore linguistic experience) affects structural priming. This is because two different languages are involved and it is therefore difficult to tease apart potential effects of nativeness from specific properties of the two different languages tested (i.e., transfer between languages that use similar or even historically related structures). Therefore, in order to investigate whether nativeness (and therefore experience) affects structural priming it is necessary to compare priming in L1 and L2 speakers of a given language. Some recent studies have investigated the effect of nativeness on priming within single languages (i.e., L1 to L1 and L2 to L2); however, the languages in the betweensubjects comparisons (i.e. L1 speakers to L2 speakers) still differed, thereby not controlling for the possibility that language-specific effects affected the results. For instance, Bernolet et al. (2007) primed L1 speakers of Dutch using Dutch, and L2 speakers of English using English, and compared the two groups. They asked participants to name the colour of pictures presented on a computer screen. Participants were primed either with an adjective-noun structure, such as The red book, or a relative clause (RC) construction such as The book that is red. The results showed that both groups were primed, and that there was no difference in the magnitude of the priming between the groups. Using the same comparative design, Schoonbaert, Hartsuiker and Pickering (2007) primed L1 Dutch and L2 English speakers to produce either PO or DO datives. Similar to Bernolet et al., they also found no difference in the magnitude of the priming they observed between the groups, suggesting that nativeness and therefore linguistic experience does not affect either the tendency to be primed or the magnitude of the priming effect. 
In contrast to the production priming experiments of Bernolet et al. (2007) and Schoonbaert et al. (2007), Nitschke et al. (2010) primed comprehension in L1 and L2 speakers of German and L1 and L2 speakers of Italian, and found that L2 speakers were primed more than L1 speakers. ${ }^{1}$ Participants in Nitschke et al. were primed to interpret ambiguous relative clauses (RCs) as object RCs, as in (1).

(1) German: $\quad$ Hier ist die Ballerina, die das Mädchen erschreckt.

'Here is the ballerina ${ }_{[S u b j / O b j]}$ that the girl ${ }_{[O b j / S u b j]}$ scares.'

Italian: $\quad$ Ecco la ballerina che spaventa la ragazza.

'Here is the ballerina ${ }_{[S u b j / O b j]}$ that scares the girl ${ }_{[O b j / S u b j]}$ '

These German NNV RCs and the Italian NVN RCs have ambiguous subject and object role assignments, but are preferably interpreted as subject RCs by L1 speakers of each language. In their experiment, Nitschke et al. used a forced choice sentence-picture matching task to prime for the interpretation of object relative clauses (German: OSV, Italian: OVS), and observed higher priming in L2 speakers. However, a closer analysis of the data in Nitschke et al. (2010) showed that the effect of nativeness was mainly driven by the Italian L1 and L2 speakers. For the German speakers there was a strong priming effect in L1 and L2 speakers, but the increase due to nativeness was not significant. It therefore appears that the effect of nativeness is subtle.

One possible explanation that draws from experience-based accounts of language is that nativeness is detectable in priming in instances where priming effects are weak in experienced speakers of the language. Let us consider this hypothesis in more detail. The experience-based learning account claims that

\footnotetext{
${ }^{1}$ Interestingly, Shin \& Christiansen (in press) recently published a study very similar to Bock \&
} Griffin (2000), but with L2 learners of English. In the condition most comparable to Bock and Griffin (dative priming, lag 4 ), they reported a priming effect of $19.92 \%$ versus Bock \& Griffin's $7 \%$ for their L1 participants. While suggestive, the data between the two studies are not directly comparable because Shin \& Christiansen only primed for one structure, and did not include an L1 comparison group. 
speakers register frequency information throughout their developmental history and that this significantly drives learning. In Chang et al.'s (2006) connectionist model, greater experience with a given structure equates to less error associated with the sequencing of each word, which equates to less weight change resulting from errorbased learning. The magnitude of priming is directly related to the amount of error in the model, such that greater error equates to greater priming. The direct prediction is therefore that L2 speakers should be primed to a greater extent than L1 speakers, because they have less experience with language and thus are less able to predict upcoming language with minimal error. There are suggestions of this in Nitschke et al.'s data, but not in other studies that have compared L1 and L2 speakers.

The contradictory findings regarding the effect of nativeness in Bernolet et al. (2007) and Schoonbaert et al. (2007) compared to Nitschke et al. (2010) are likely to be rooted in three specific methodological differences. Firstly, Nitschke et al. compared L1 and L2 speakers on a common language: L1 German speakers were compared to L2 German speakers on German prime-target pairs, and L1 and L2 Italian speakers were tested in Italian. In contrast, Bernolet et al. and Schoonbaert et al. compared L1 speakers of Dutch, who were tested in Dutch, to L2 speakers of English, who were tested in English. Thus it is possible that potential effects of nativeness were not observed in the latter two cases because of language-specific effects caused by comparing groups that were tested on two different languages. The second difference is that Bernolet et al. and Schoonbaert et al. primed production, whereas Nitschke et al. primed comprehension. The third and potentially most important methodological difference is that Bernolet et al. and Schoonbaert et al. used priming designs where competing structures were primed within participants. That is, subsequent prime items primed for different structures (i.e. adjective-noun constructions vs. RCs in Bernolet et al., and DO vs. PO datives in Schoonbaert et al.). In contrast, Nitschke et al. primed participants for only one type of interpretation throughout the experiment (i.e., object RCs). Earlier work has suggested that priming accumulates if the same structure has been primed repeatedly (Hartsuiker \& Westenberg, 2000; Kaschak, 2007; Kaschak, Loney \& Borreggine, 2006; Thothathiri $\&$ Snedeker, 2008). If priming does indeed accumulate, then using the same prime type throughout the experiment should increase the priming effect. It is thus possible that effects of nativeness in structural priming are relatively subtle compared to the 
overall priming effect, and are only evident through accumulation over multiple repetitions.

The question of whether priming is affected by nativeness bears on the more fundamental question concerning the mechanisms that drive priming. There is evidence that priming effects can persist over time delays (Branigan, Pickering, Stewart \& McLean, 2000b) or intervening items (Bock et al., 2007; Bock \& Griffin, 2000; Hartsuiker, Bernolet, Schoonbaert, Speybroeck \& Vanderelst, 2008). It has also been suggested that priming is more successful with structures that have low type frequency (e.g., the passive in English) than with items that have high type frequency (e.g., the active in English, Chang, et al., 2006; Ferreira \& Bock, 2006; MacDonald \& Christiansen, 2002). Thus, susceptibility to priming should decrease as experience with the primed structures increases. That is, learning-based explanations of priming explicitly predict that, all things being equal, L2 speakers should be more susceptible to priming than L1 speakers. However, there should be no difference in the magnitude of priming in L1 and L2 speakers if priming is driven by activation, since the assumption is that speakers who know a structure in a given language will activate structures to the same degree regardless of nativeness. This is because the priming-as-activation explanation does not predict that usage affects representation, since activation decays rapidly (less than a second, Roelofs, 1992).

In the current paper we address this issue using nativeness as a proxy variable for experience. That is, in this case experience concerns the long-term accumulation of linguistic knowledge over a speaker's developmental history. We postulated the working hypothesis that effects of nativeness (and therefore experience) should only be observed in instances where priming effects are normally weak or not observed in L1 speakers. To investigate whether L2 speakers are indeed primed more easily than L1 speakers we manipulated the conditions that have been reported to determine the likelihood of finding a priming effect: (i) the lexical boost, (ii) frequency of the prime structure, and (iii) animacy differences. We consider each of these issues in turn.

The lexical boost refers to the fact that open class lexical overlap between prime and target items results in larger priming effects. It is arguably the most consistently reported influence on structural priming. The effect has been shown in 
comprehension (Arai, van Gompel \& Scheepers, 2007; Branigan, et al., 2005) as well as in production (Cleland \& Pickering, 2006; Corley \& Scheepers, 2002; Pickering \& Branigan, 1998).

Frequency of the prime structure has also been shown to affect priming. For instance, Hartsuiker, Kolk and Huiskamp (1999) primed Dutch speakers to use locatives in sentence-initial or sentence-final positions; for example, $A$ ball is on the table vs. On the table is a ball. Baseline data showed that expressions with sentence-initial locatives are significantly less frequent than sentence-final locatives. However, priming only affected the participants' use of the lower frequency sentence-initial locatives, and did not affect the use of the high frequency sentence final-locatives. A similar pattern was found by Hartsuiker and Westenberg (2000) with Dutch subordinate clauses. Similarly, when priming for the use of active and passive constructions in English, the effect has been found to be greater with passives, which are comparatively low in frequency compared to actives (Bock \& Loebell, 1990; Hartsuiker \& Kolk, 1998b; Hartsuiker, et al., 2004). In a similar vein, Wells, Christiansen, Race, Acheson and MacDonald (2009) conducted a training study whereby native English-speakers read equal numbers of subject and object RCs over the course of a week. In written English object RCs are much lower in frequency than are subject RCs (Gennari \& MacDonald, 2008; Roland, Dick \& Elman, 2007). Wells et al. found that reading performance in a post-training self-paced reading task improved more for the less frequent object relative clauses than for the comparatively more frequent subject relative clauses.

Noun Phrase (NP) Animacy has been shown to affect language processing (Kidd, Brandt, Lieven \& Tomasello, 2007; Gennari \& MacDonald, 2008; Mak, Vonk \& Schriefers, 2002; Prat-Sala \& Branigan, 2000; Prat-Sala, Eacute, Shillcock \& Sorace, 2000). With respect to priming, Bock et al. (1992) reported that participants prefer to assign the same grammatical function to NPs in their descriptions of targets depending on the animacy configuration of the prime. That is, primes with inanimate subject arguments elicited more target descriptions that contained inanimate subject arguments. Given these results it can be assumed that if animacy does affect priming in comprehension then priming effects are more likely to be observed in 
cases where the NPs in primes and targets have the same animacy properties than when they do not (see Snider, 2008, 2009).

Taking into consideration these three variables, it is reasonable to suggest that Nitschke et al.'s (2010) study provided the optimum conditions to observe a priming effect. Firstly, there was open-class lexical overlap between prime and target items. Secondly, their primes had low type frequency because the object RCs they tested contained an animate head noun, which are the rarest kind of object RCs in both German and English (Fox \& Thompson, 1990, 2007; Gennari \& MacDonald, 2008; Roland, et al., 2007). Thirdly, all prime and target sentences contained animate NPs. The suggestion here is that no effect of nativeness was observed in the case of the German speakers because the optimal conditions with which to observe a priming effect were met.

In the current paper we explore the hypothesis that linguistic experience does have an effect on priming, but that it is only detectable in instances where priming effects are weak or non-existent in highly experienced speakers (i.e., L1 adults). Increasing experience with a language may lead to entrenchment of syntactic knowledge, making it less susceptible to priming. To test this, the following four experiments systematically eliminated open-class lexical overlap, increased type frequency, and introduced animacy differences to prime-target pairs. It was hypothesised that the manipulation of these three variables should weaken the overall priming effect. As a consequence, we predicted that an effect of nativeness and therefore of linguistic experience would be observed, such that L2 speakers of German would be primed in instances where L1 speakers of Germans would not.

\section{Experiment 1: No open-class overlap}

Experiment 1 primed L1 speakers of German and L2 speakers of German with L1 English to interpret ambiguous German NNV relative clauses (RCs) as object $\mathrm{RCs}$; that is, an object-subject-verb (OSV) mapping. An example for an ambiguous German NNV RC is provided in (2). 
(2) Hier ist die Ballerina, die das Mädchen erschreckt.

'Here is the ballerina ${ }_{[S u b j / O b j]}$ that the girl $_{[O b j / S u b j]}$ Scares.'

In German syntactic roles are overtly marked for case on determiners and, in the case of RCs, on relative pronouns. Sentence (2) is ambiguous between a subject and object RC because feminine and neuter NPs have the same form for nominative and accusative case. However, L1 German speakers prefer the NP1 to be interpreted as the subject (= subject reading) rather than as the object (= object reading. As discussed, Nitschke et al. (2010) successfully primed L1 and L2 speakers of German to significantly increase the numbers of OSV RCs. Experiment 1 replicated Nitschke et al.'s (2010), with one important difference: there was no open class lexical overlap, thus removing one likely contributing factor to the priming effect.

\section{Method}

\section{Participants}

Forty-eight ( $\mathrm{N}=48$ ) German-speaking adults participated: 24 L1 Germans and 24 L1 English speakers with L2 German. The L1 Germans were on average 21 years old ( $\min 18, \max 27$ years). Eighteen were female. Six of the initial $24 \mathrm{~L} 2$ Germans failed a vocabulary test (see Materials section) and were replaced. The final 24 L2 Germans were native English speakers with a mean age of 22 years (min: 19, max: 27). Fifteen were female. One reported to have started learning German and French at five years of age at primary school, the other 23 had not started learning any second language before the age of seven. On average the L2 speakers had studied German for nine years (min: 4, max: 16 years). One participant reported to have lived in Germany for 5.5 years at the time of testing, one had not been to a German speaking country for longer than four weeks at a time, and the others had spent an average of seven months (min: 1.5, max: 12) working or studying in Germany or Austria.

\section{Materials}


The items of interest were syntactically ambiguous German NNV relative clauses that could be interpreted either with an SOV or an OSV mapping, as shown in example (2). The experiment comprised of 166 sentences, each followed by one pair of pictures (see Figure 1). Sixty-four of these sentences were ambiguous NNV $\mathrm{RCs}$, of which 16 were disambiguated because one picture displayed the object reading while the other picture did not correspond to the content of the prime sentence. The remaining 48 sentences were not disambiguated but were followed by two pictures that displayed both possible readings, the subject and the object reading. In any one version of the experiment, 16 of the ambiguous $\mathrm{RC}$ sentences were presented in a baseline phase of the experiment, 16 were paired with the prime trials to constitute the test phase, and the remaining 16 were used in a post-test phase, where no further priming took place.

The 64 experimental NNV RCs were assembled out of 16 different human characters and 16 different verbs. In German, nominative and accusative case marking on the relative pronoun and on the definite article accompanying a masculine noun is morphologically distinct and disambiguates syntactic role assignment. Therefore, all the 16 human characters were of feminine or neuter gender, where there is ambiguity between nominative and accusative case. The remaining 102 of the total 166 items served as fillers that comprised an array of different syntactic structures (e.g. actives, passives, intransitives and transitive sentences with ambiguous prepositional phrase attachments). The fillers were interspersed to disguise the aim of the study.

We also prepared a vocabulary questionnaire for the L2 participants to assess their lexical knowledge and to familiarize L2 participants with unknown words prior to the experiment. The list comprised of 50 nouns and verbs that occurred in the test items (see Appendix). Participants were excluded if they failed to correctly translate 30 of those 50 words. We made the relatively high allowance of 20 mistakes in the vocabulary test as the words occurred in random order without any contextual cues. If participants made no more than 20 mistakes they were told the meanings of the words they did not know and were asked to write them down for practice. The participants included in Experiment 1 made on average 13 mistakes (min: 0, max: 19). 


\section{Procedure}

The L2 participants were given the vocabulary questionnaire first. The structural priming task was presented using E-Prime (MacWhinney, James, Schunn, Li \& Schneider, 2001). Participants were told that the study investigated second language processing and that they would be required to read sentences and select a matching picture for each from an array of two pictures by pressing a button on a button box. Pictures and sentences did not time out; therefore opting out from making a choice was not possible. Prior to the task each participant was presented with six unambiguous practice items.

The picture selection task was divided into three continuous phases: (i) a baseline phase, (ii) a prime phase, and (iii) a post-test phase. All three phases contained pairs of ambiguous NNV relative clauses separated by two to five fillers. In the baseline phase, all ambiguous RCs were followed by pictures providing both the OSV reading and the SOV reading of each sentence. This phase served to confirm that the unprimed L1 and L2 German speakers prefer the SOV reading of ambiguous German NNV RCs. Any significant increase in OSV readings following the baseline phase would indicate an effect of priming.

During the prime phase, the first $\mathrm{RC}$ of each $\mathrm{RC}$ pair was disambiguated to an object reading and served as the prime. The disambiguation was achieved by offering one picture displaying a scene corresponding to the less preferred OSV mapping and another picture in which the role assignment also corresponded to the OSV mapping but in which the verb did not match that of the sentence (see top panel of Figure 1). The second RC of each RC pair, the target, provided both interpretations: the OSV mapping (i.e., object $\mathrm{RC}$ reading) and the SOV mapping (i.e., subject $\mathrm{RC}$ reading; see bottom panel of Figure 1). Following Branigan et al. (2005), the logic of the procedure was that by restricting the choice to OSV mappings in the prime items participants would be primed to select the OSV picture of the ambiguous NNV RCs in the target items, even though the normally preferred SOV mapping was also available. 
- INSERT FIGURE 1 ABOUT HERE -

Eight lists were created out of the 166 items to fully balance the positions of all items over the three phases of the experiment. Furthermore, the positions of the pictures to be selected (left vs. right) were counterbalanced across the lists.

\section{Results}

The proportions of OSV choices are displayed in Figure 2. For both speaker groups the graph shows an increase of OSV choices from the baseline phase to the target phase and from the baseline phase to the post-test phase. The L2 Germans made more OSV choices at baseline than the L1 Germans, which is likely to reflect L1 transfer from English, where the NNV surface order is unambiguously an OSV relative clause (for detailed discussion on L1 transfer see Nitschke et al. 2010).

\section{- INSERT FIGURE 2 ABOUT HERE -}

The data were analysed using Generalized Linear Mixed Models (GLMM) (Baayen, et al., 2008; Jaeger, 2008), which were calculated using the Ime4 package (version 0.999375-33) for Linear Mixed Effects (Bates \& Maechler, 2010) in the program R, version 2.10.1 (R Development Core Team, 2009).

We followed Jaeger (2008) and aimed to include random slopes and random intercepts into the GLMM as shown in the box $\mathrm{R} 1$ :

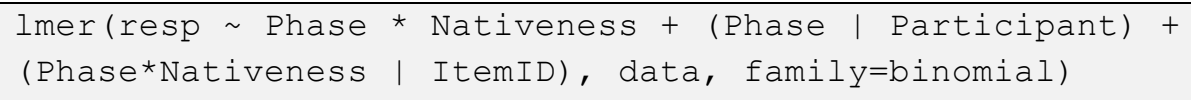

R 1: GLMM with random slopes and random intercepts 
However, the full model full model as shown in the box $\mathrm{R} 1$ was overspecified and did not converge ('singular convergence') ${ }^{2}$. The model therefore had to be simplified. To be maximally conservative we therefore individually tested the effects of each random slope component. This was done by comparing a 'null model' that comprised only of the fixed effects and of the random intercepts with more complex models in which we included the random slopes components one at a time. The interactions were included in the models at the same time as the main effects, as shown in box $\mathrm{R} 2$.

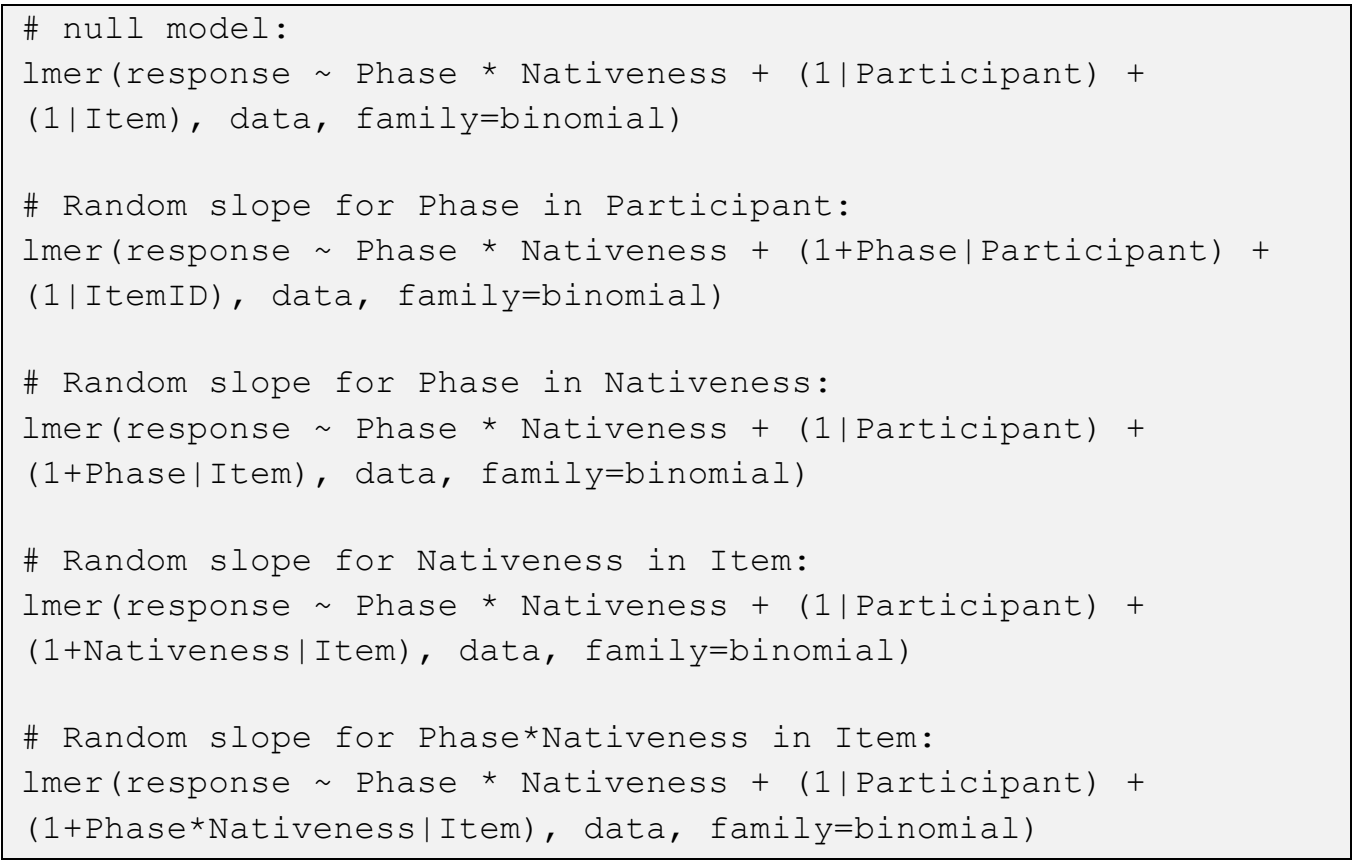

\section{R 2: Test of the effects of the random slopes}

The full model was compared against each of the models that included one random slope in likelihood ratio tests. When the likelihood ratio test revealed a $p$ value larger than 0.20 it was not included in the subsequent analyses (see Jaeger,

${ }^{2}$ Singular convergence means that the model is trying to fit more parameters than the data allow. In the case of discrete dependent variables (DV), such as in the present experiments, singular convergence can occur when only one type of response occurs (i.e., if there are only OSV or SOV choices). A remedy for the convergence problem is to make the model less complex. This can be done by taking out parameters that are the least important for the predictability of the model as measured by the $p$-value after individual testing. 
2008). For Experiment 1, only Phase in Participant had a $p$-value smaller than 0.20 . Phase in Item, Nativeness in Item and Phase by Nativeness in Item had $p$-values larger than 0.20 . Therefore, the full and the null model also only included random slopes for Phase in Participant, as shown in text box R 3.

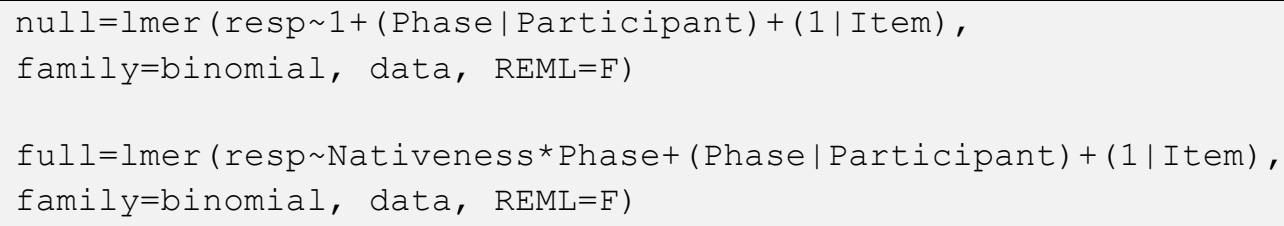

R 3: The full and the null GLMM for the analysis of Experiment 1

A likelihood ratio test showed that the full model fitted the data better than the null model that only included the random effects $\left(\chi^{2}(5)=64.78, p<.001\right)$. This indicated that the predictors included in the full model accounted for the data better than the null model and that further analysis was in order. Comparing the full model and a reduced model from which the interaction was removed showed that the phase by nativeness interaction was not significant $\left(\chi^{2}(2)=2.623, p=.27\right)$. The interaction was therefore removed from further analysis.

We next investigated whether there was an overall priming effect of phase. In order do so the model that included phase and nativeness (and the random effects) was compared to a reduced model comprising only nativeness and the random effects. This comparison was significant $\left(\chi^{2}(2)=20.63, p<.001\right)$, indicating that the numbers of object readings differed between the phases. To locate the effect of phase GLMMs were built that contained phase and nativeness as fixed factors but from which either the post-test phase or the prime-phase was removed. The results showed that the numbers of OSV interpretations rose significantly from the baseline phase to the prime phase, indicating an effect of priming (estimate $=1.77, S E=0.35$, $z=5.09, p<.001)$. The numbers of OSV choices were also found to have risen significantly from the baseline phase to the post-test (estimate $=1.22, \mathrm{SE}=0.45, \mathrm{z}=$ $2.72, p<.001)$. The effect of OSV priming therefore lasted into the post-test phase where no further primes were administered, which suggests long-term priming. 
The final model for the data of Experiment 1 is shown in Table 1. The model shows that the effect of nativeness was significant (estimate $=3.03, \mathrm{SE}=0.38, z=$ $7.88, p<.001$ ), which indicates that overall the L2 speakers made more OSV mappings than the L1 speakers. However, since the magnitude of priming did not differ between the two groups, as evident from the non-significant interaction between phase and nativeness, it must be concluded that there was no difference in priming between the L1 and L2 speakers.

\section{- INSERT TABLE 1 ABOUT HERE -}

\section{Discussion}

In Experiment $1 \mathrm{~L} 1$ and L2 speakers of German were primed to interpret ambiguous German NNV RCs as object relatives (OSV) in the absence of open class lexical overlap. Consistent with Nitschke et al. (2010), the results showed a priming effect in L1 and L2 speakers that lasted over the post-test phase, where no additional primes were administered. These findings add to earlier work where structural priming has been found in the absence of open class lexical overlap between prime and target (Bock, et al., 2007; Bock \& Griffin, 2000; Branigan, et al., 2000b; Scheepers \& Crocker, 2004), but is inconsistent with studies that found open class lexical overlap to be essential for structural priming to occur (Arai, et al., 2007; Branigan, et al., 2005). In particular, the results add evidence to suggest that priming through comprehension is possible in the absence of open class lexical overlap in L1 speakers (see also Scheepers \& Crocker, 2004; Thothathiri \& Snedeker, 2008) as well as in L2 speakers. We return to this issue in the General Discussion.

However, Experiment 1 provided no indication that priming was affected by nativeness. We predicted that the effect of nativeness may only be observed in instances where the priming effect is weak. The priming effect in Experiment 1 persevered over the post-test phase in both speaker groups, suggesting that the effect was relatively strong. Experiments $2-4$ made further attempts to reduce the priming effect by manipulating (i) the ambiguity of the prime, (ii) the animacy 
properties of the NPs in the prime sentences, and (iii) the frequency of prime sentences in the ambient language.

\section{Experiment 2: Morphologically disambiguated primes}

While in Experiment 1 the prime sentences were ambiguous RCs, Experiment 2 used disambiguated object RCs as prime sentences. This was done because the unambiguous primes in Experiment 1 may have alerted the participants to the experimental manipulation and thus increased the chances of observing a priming effect. The dominant interpretation of ambiguous German NNV RCs is an SOV reading (Mak et al., 2002; Nitschke et al. 2010); therefore the participants were likely to have interpreted the prime sentences as subject readings during reading. However, in this case there would be a mismatch between the sentence and subsequent pictures, as during the prime trials the pictures only provided scenes with the object reading (OSV) of the prime sentences, potentially alerting participants to the manipulation. Such negative feedback could have been a powerful source of error, leading to the priming effect in Experiment 1 (see Carroll \& Swain, 1993; McDonough, 2005). It may also have contributed to priming effects found in other studies that have used the same method (e.g. Branigan, et al., 2005; Nitschke, et al., 2010; Raffray, Pickering \& Branigan, 2007). Experiment 2 primed participants using unambiguous object RCs in order to rule out this possible explanation.

The sentences used as primes in Experiment 2 were disambiguated by case marking. In German, case marking on the masculine definite article and the masculine relative pronoun is morphologically distinct between accusative case (den) and nominative case (der), and therefore disambiguates transitive constructions. For example, consider (3) and (4).

(3) a OSV Hier ist die Frau, die der Mann küsst.

'Here is the woman ${ }_{[O b j]}$ that the $\operatorname{man}_{[S u b j]}$ kisses'

b SOV Hier ist die Frau, die den Mann küsst. 
'Here is the woman ${ }_{[S u b j]}$ that the $\operatorname{man}_{[0 b j]}$ kisses'

(4) a OSV Hier ist der Mann, den die Frau küsst.

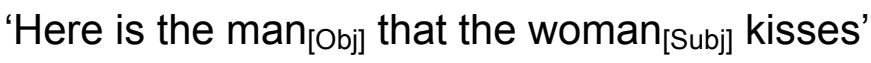

b SOV Hier ist der Mann, der die Frau küsst.

'Here is the $\operatorname{man}_{\left[S_{u b j]}\right.}$ that the woman ${ }_{[O b j]}$ kisses'

Experiment 2 used object RCs such as (3a) and (4a) to prime for OSV mappings of ambiguous NNV RCs (such as Hier ist die Ballerina, die das Mädchen erschreckt. 'Here is the ballerina ${ }_{[S u b j / O b j]}$ that the girl $_{[O b j / S u b j]}$ scares.'). The positions of the disambiguating male NP is different in sentence $3 a$ and $4 a$. Experiment 2 used both of these variations in order to balance potential semantic biases.

Because of the unambiguous case marking in the primes, participants were expected to read the sentences as OSV RCs and subsequently choose the picture with the OSV scene without first interpreting the prime sentence as an SOV. It has been shown that upcoming syntactic roles are anticipated and that this happens even before encountering the verb (see Kaiser \& Trueswell, 2004; Kamide \& Mitchell, 1999; Knoeferle, Crocker, Scheepers \& Pickering, 2005). Thus, participants should predict the OSV structure well before seeing the pictures. Additionally, since these prime sentences were unambiguous, it was unlikely that reanalyses were necessary upon the presentation of the pictures. Thus, the likelihood that the participants would become aware of the experimental aims was strongly reduced in Experiment 2 as compared to Experiment 1. Therefore, if the priming effects observed in Experiment 1 and Nitschke et al. (2010) depended on negative feedback through the mismatch between the read sentences and the provided choice of pictures, the priming effect in Experiment 2 should be diminished. If, however, a priming effect comparable to Experiment 1 is observed then we can be confident that: (i) the potential negative feedback provided in Experiment 1 did not drive the priming effect, and (ii) the picture selection task in Experiment 1 and other forced choice picture matching tasks elicit genuine (i.e., unconscious, Seger, 1994) priming effects. If we observe an effect of nativeness on priming (i.e. an interaction between phase and nativeness) 
then this would suggest that speakers with different amounts of experience (L1 vs. L2 speakers) are differently sensitive to feedback cues or that L2 speakers are simply less sensitive to morphological information such as case marking. In particular, it is conceivable that, whereas the negative feedback provided in Experiment 1 was powerful enough to prime both L1 and L2 speakers, the lack of this mechanism in Experiment 2 will decrease priming in L1s.

Method

\section{Participants}

Twenty-four ( $\mathrm{N}=24)$ new L1 Germans were tested. The mean age was 20 years (range: $18-24$ ). Seventeen were female. None reported to have learned any second language before the age of eight. Twenty-four $(N=24)$ new L2 Germans were also tested. Two of them had to be replaced because they made more than 20 mistakes in the vocabulary pre-test. The final 24 L2 Germans made on average 11 mistakes in the vocabulary test (min: 0 , max: 18) and had a mean age of 22 years (min: 20, max: 24). None had studied any second language before the age of seven and on average they had studied German for eight years at the time of testing (min: 2, max: 12 years). The L2 Germans had spent an average of eight months in Germany or Austria (min: 2, max: 24 months). Fifteen were female.

\section{Materials}

Experiment 2 differed from Experiment 1 in that the 16 prime items were replaced by new items with morphologically disambiguated object RCs. In eight of these prime sentences the NP1 was female and the NP2 was male (as in 3a) and in the other eight the NP1 was male and the NP2 female (as in 4a). All other items were identical to those in Experiment 1 and again there was no open class lexical overlap between primes and targets.

\section{Procedure}


The procedure was identical to that of Experiment 1. The order of the 16 new prime items was balanced over the eight lists of items and care was taken to avoid overlap of the NPs or the main verb.

Results

Figure 3 shows the results of Experiment 2. There was an increase of the object readings from the baseline phase to the prime phase for both speaker groups. From the prime phase to the post test the numbers of ORs slightly decreased in both groups but were still larger than in the baseline phase.

\section{- INSERT FIGURE 3 ABOUT HERE -}

The data were analysed using the same methods used to analyse Experiment 1. First, random slopes were tested for their effect on the model. The outcome was similar to Experiment 1 in that phase in participant was the only random slope with an effect on the outcome. The full and the null GLMMs where therefore built as those of Experiment 1. A likelihood ratio test revealed that the full model fitted the data better than the null model $\left(\chi^{2}(5)=66.39, p<.001\right)$. The two-way interaction between phase (baseline, prime phase and post-test phase) and nativeness (L1, L2) was not significant $\left(\chi^{2}(2)=0.02, p=.99\right)$. The interaction was therefore removed from further analysis.

We next investigated whether there was an overall effect of phase by comparing the full model with phase, nativeness and the random effects against a reduced model comprising only nativeness and the random effects. The comparison was significant $\left(\chi^{2}(2)=21.45, p<.001\right)$, suggesting that the number of object readings clearly differed between the phases. Further investigation of the factor of phase revealed a significant effect of OSV priming from the baseline phase to the prime phase (estimate $=1.43, S E=0.31, z=4.68, p<.001)$, and from the baseline 
phase to the post-test phase (estimate $=0.93, S E=0.35, z=2.63, p=.009$ ), indicating that the effect of OR priming lasted over the post-test phase.

The final model of the data from Experiment 2 is shown in Table 2. As can be seen, the effect of nativeness was again significant (estimate $=3.07, \mathrm{SE}=0.37, \mathrm{z}=$ $8.42, p<.001$ ), which indicates that overall the L2 speakers made more OSV choices than the L1 speakers. However, as in Experiment 1, there was no phase by nativeness interaction, suggesting that priming did not differ between the L1 and L2 speakers.

\section{- INSERT TABLE 2 ABOUT HERE -}

To investigate whether using ambiguous or disambiguated prime sentences had an effect on the outcome of priming, Experiments 1 and 2 were compared directly. It was first determined which random slopes were meaningful for the analysis and should therefore be included into the model. Next, the full model was built and compared to a null model (see the text box $R 4$ ). The likelihood ratio test revealed that the full model fitted the data better than the null model $\left(\chi^{2}(11)=130.42\right.$, $p<.001)$, indicating that further analysis was necessary. Next the three-way interaction of nativeness, phase and experiment was tested by comparing the full model containing the interaction and main effects of these fixed factors, and participants and items as random factors, to a reduced model for which the maximum level of interactions between nativeness, phase and experiment was set to two, see R 4.

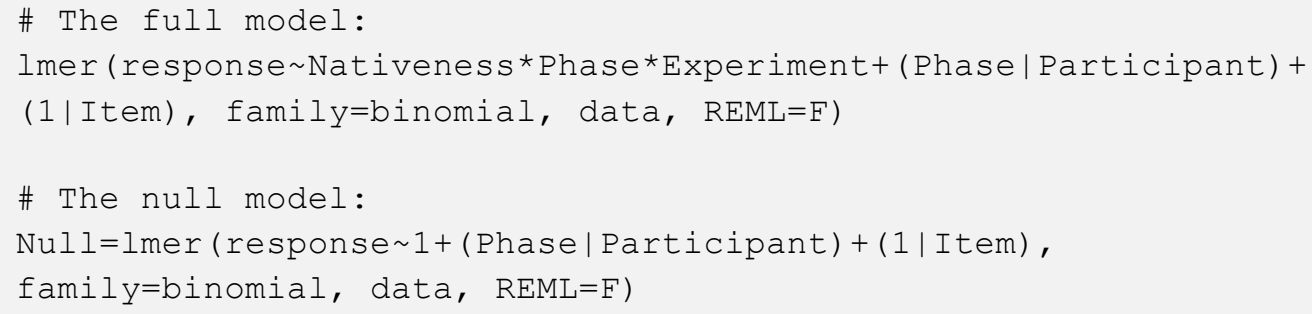




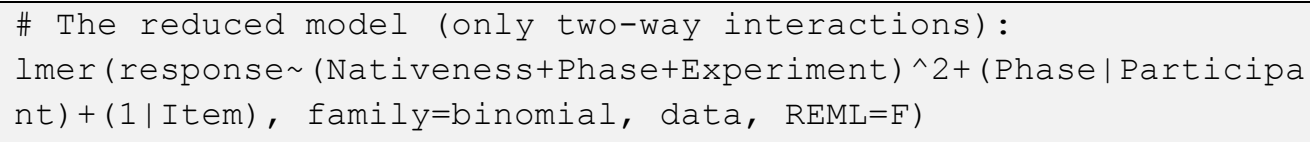

R 4: full model (Full) and reduced model (Red) for the investigation of the three way interaction of Nativeness* ${ }^{*}$ hase ${ }^{*}$ Experiment

The full model did not fit the data significantly better than the reduced model $\left(\chi^{2}(2)=0.811, p=.67\right)$, indicating that the three way interaction was not significant. Next all potential two-way interactions were investigated by setting the maximum level of interactions to two in the full model and comparing it to a new reduced model that contained no interaction. The likelihood ratio test showed that none of the potential two-way interactions were significant $\left(\chi^{2}(5)=2.50, p=.78\right)$. This indicates that using disambiguated prime sentences did not significantly change the outcome of the experiment. The non-significant interaction data of Experiment 1 and 2 are plotted in Figure 4.

\section{- INSERT FIGURE 4 ABOUT HERE -}

Discussion

Experiment 2 again showed priming effects in L1 and L2 speakers despite using disambiguated prime items. The priming effect lasted over the post-test phase, where no further primes were administered. This outcome is similar to that of Experiment 1, where the prime sentences were ambiguous and potentially first analysed by the participants as SOV structures. The results of Experiment 2 therefore suggest that the potential negative feedback provided in Experiment 1 was not the driving force of the priming effect. Furthermore, since there was no significant difference between priming of L1 and L2 speakers, this feedback mechanism was not found to differentially affect the two speaker groups. The interaction between phase and nativeness was not significant even though the proportions of OSV 
choices increased about three times as much for the L2 speakers than it did for the L1 speakers, as can be seen in Figure 3. Since the GLMMs we used were very conservative we also tested this result using arcsine transformed data in an ANOVA. We obtained the same result. When comparing the data of Experiment 2 in Figure 3 with the data of Experiment 1 in Figure 2 it can be seen that it was the L1 speakers who where nominally (but not statistically) affected by the changed condition of the experiment. This observation that L1 speakers seem to be more sensitive to changed experimental conditions suggests that L2 speakers' priming might be more robust than that of $\mathrm{L} 1$ speakers. The results from the additional between-experiment analyses therefore suggest that forced choice picture matching tasks that use ambiguous prime sentences ahead of the choice of disambiguating pictures, as in Experiment 1, yield genuine priming effects (see also Branigan, et al., 2005; Nitschke, et al., 2010; Raffray, Pickering \& Branigan, 2007).

\section{Experiment 3: Animacy disambiguation, high type frequency}

Experiments 3 and 4 investigated the role of type frequency and animacy information in priming in L1 and L2 speakers. Experiment 3 used 16 NNV RC primes that were syntactically ambiguous but semantically disambiguated to OSV RCs because they contained an inanimate head noun, as in sentence (5).

(5) Hier ist das Eis, das die Frau isst.

'Here is the ice cream ${ }_{[O b j]}$ that the woman eats ${ }_{\left[S_{u b j]}\right.}$

Despite its syntactic ambiguity, sentence (5) can only be plausibly interpreted with the ice-cream as the object and the woman as the subject of the sentence. Previous research has shown that NP animacy affects language processing (Brandt, Kidd, Lieven, \& Tomasello, 2009; Mak et al., 2002; Traxler, Morris \& Seely, 2002). Furthermore, there are indications that the animacy distribution between the prime and the target items affects the outcome of priming (Bock et al. 1992, Snider, 2008). 
It can therefore be assumed that animacy repetition should be more likely to yield a priming effect, whereas differences in animacy between primes and targets should reduce the effect. As such, there is a chance that the animacy manipulation in the prime sentences will reduce the overall strength of the priming effect, which could therefore reveal an effect of nativeness.

Sentence (5) differs from the primes in Experiments 1 and 2 because the first NP, the head noun, is inanimate. Not only does this prime sentence differ in animacy, it also differs in type frequency. Corpus studies of German have shown that object RCs with inanimate head nouns are the most common type of German OSV RCs (Kidd, et al., 2007; Mak, et al., 2002; Zubin, 1979). This also means that, in comparison to (5), the NNV RC primes used in Experiment 1 and 2 had low type frequency and were therefore atypical. According to the experience-based approach, (e.g. Chang, et al., 2006; Mitchell, Cuetos, Corley \& Brysbaert, 1995), structures that are low in frequency result in greater priming because there is a greater difference between the predicted structure and what is processed, thus leading to greater updating of usage statistics via error-based learning (Bock \& Loebell, 1990; Hartsuiker \& Kolk, 1998b; Hartsuiker, et al., 1999; Hartsuiker, et al., 2004; Wells, et al., 2009). Therefore, in comparison to Experiments 1 and 2, Experiment 3 manipulated two variables: animacy and type frequency. Again, the assumption was that both increasing the type frequency of the prime and providing an animacy mismatch between prime and target would weaken the overall priming effect, thus increasing the likelihood that we would observe a differential effect of nativeness in our data

\section{Method}

\section{Participants}

Twenty-four L1 Germans were tested, none of whom participated in any of the earlier experiments. The mean age was 23 years (range: 20 - 28). Seventeen were female. Twenty-four new L2 German speakers were also tested. One L2 participant was replaced because he made more than 20 mistakes in the vocabulary pre-test. The final $24 \mathrm{~L} 2$ Germans made a mean of 13 mistakes in the vocabulary pre-test (min: 1, max: 19) and had a mean age of 21 years (min: 19, max: 23). One started learning French at the age of 5 years; the remaining 23 had not studied any second 
language before the age of 7 years. On average the L2s had studied German for eight years ( $\min : 3$, max: 11). Two reported to have stayed in Germany or Austria for no longer than one month at a time, while the remaining $22 \mathrm{~L} 2$ Germans had been working or studying for an average of eight months in Germany or Austria (min: 2, max: 12 months). Twelve of the final 24 L2 Germans were female.

\section{Materials}

The 16 prime items of Experiment 1 were replaced by new items with semantically unambiguous object RCs that had an inanimate NP1, such as sentence (5). Because the prime sentences in Experiment 3 had animate agents that acted on inanimate patients different verbs were needed. While Experiment 1 and 2 used verbs such as scare or chase that can have animate patients, Experiment 3 used verbs that can plausibly have inanimate patients, such as eat or read. One of the two item pictures displayed the correct object reading interpretation and the other picture was again unrelated. The remaining items were identical to those of Experiment 1.

\section{Procedure}

The procedure was identical to that of Experiment 1. There was again no open class overlap between the primes and the targets.

\section{Results}

The results of Experiment 3 are displayed in Figure 5 . The graph shows that the numbers of object readings decreased over the course of the experiment for L1 speakers. For L2 speakers the numbers of OSV choices increased from the baseline phase to the prime phase and slightly decreased from the prime phase to the posttest phase. However, the proportions of OSV choices were still higher in the post-test phase than they were in the baseline phase. 
- INSERT FIGURE 5 ABOUT HERE -

To investigate Experiment 3 we again first established the random slopes that had an effect on the model. The phase variable in participant and nativeness in item both had $p$-values below .20. The full and the null GLMMs were therefore built as shown in the box $\mathrm{R} 5$

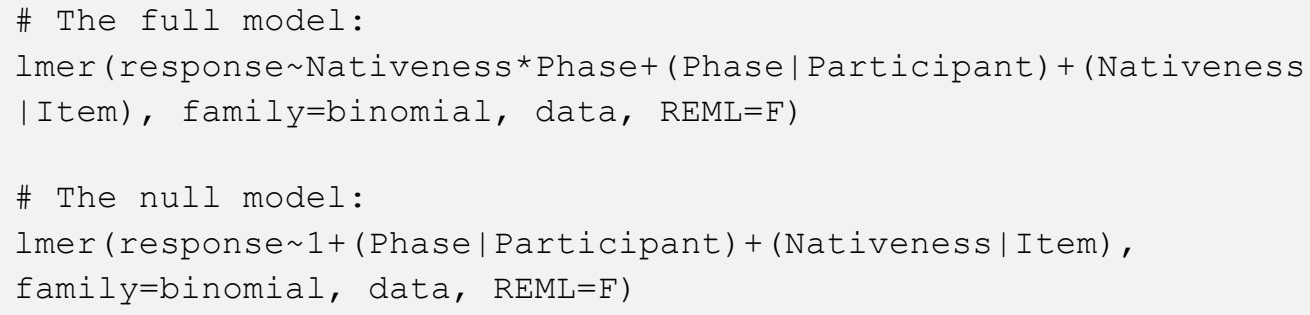

R 5: full and null model after establishing random slopes for Experiment 3

A likelihood ratio test showed that the full model fitted the data significantly better than the null model $\left(\chi^{2}(5)=49.20, p<.001\right)$. In the next step the two-way interaction between phase (baseline, prime phase and post-test phase) and nativeness ( $L 1, L 2)$ was tested by comparing the full model against a reduced model that contained no interaction. The interaction was significant $\left(\chi^{2}(2)=14.89, p<.001\right)$, suggesting that $L 1$ and $L 2$ groups differed in their response to the priming manipulation.

To investigate the pattern of the interaction we split the data into subsets for L1 and L2 speakers. As Figure 5 shows, the number of OSV choices decreased over the course of the experiment in the L1 speakers. To investigate whether this decrease was significant we compared a full model of the L1 data against a null model of the L1 data. The likelihood ratio test showed that there was a significant effect of phase $\left(\chi^{2}(2)=8.80, p=.01\right)$. We next carried out post-hoc tests to identify the location of the effect. This was done by excluding first the post-test data and then the prime phase data from the full L1 model. The results showed that for the L1 speakers the decrease of OSV choices was significant from the baseline-phase to 
the prime phase (estimate $=-1.13, S E=0.46, z=-2.45, p=.01$ ), and also from the baseline phase to the post-test phase (estimate $=-1.09, S E=0.36, z=-3.07, p$ $=.002)$.

According to Figure 5 the L2 speakers behaved differently to the L1 speakers in that the L2 numbers of OSV choices increased after the baseline phase. A likelihood ratio test comparing a full $L 2$ model with a null $L 2$ model showed that there was a marginally significant effect of phase $\left(\chi^{2}(2)=5.50, p=.064\right)$. The post-hoc tests showed that the effect of phase was significant from the baseline phase to the prime phase (estimate $=0.79, S E=0.32, z=2.48, p=.01$ ). The effect was, however, not significant from the baseline phase to the post test phase (estimate $=0.35, S E=$ $0.30, z=1.17, p=0.24)$.

Because the interaction between phase and nativeness was significant, the model that best fits the data of Experiment 3 is the full model which includes all fixed (nativeness, phase) and random (participant, item) effects, and also includes the two-way interaction between the fixed effects (phase*nativeness). The full model is shown in Table 3.

- INSERT TABLE 3 ABOUT HERE -

\section{Discussion}

In Experiment 3 participants received primes that (i) were high in type frequency compared to those used in Experiments 1 and 2, and (ii) contained an animacy mismatch with the target structure. The results showed that although the L1 participants were not primed for OSV mappings, the L2 participants were, which resulted in a phase by nativeness interaction. The results from Experiment 3 therefore support our hypothesis that non-native speakers should be more susceptible to priming and that this effect is most likely identifiable if the overall strength of priming as measured in L1 speakers is relatively weak or nonexistent. 
The L1 speakers in Experiment 3 showed a negative priming effect from the baseline to the post-test phase, while the L2 speakers were successfully primed. This 'anti-priming' effect in the L1 speakers suggests that the prime sentences were sufficiently different from the targets for the L1 speakers to process them as unrelated. Instead, it appears that the decrease in OSV readings across the experiment was due to the L1 participants consolidating their preference for the subject $R C$ reading of the ambiguous targets.

The results of Experiment 3 suggest that priming is affected by linguistic experience, as measured by a speaker's nativeness. However, the results do not unequivocally demonstrate that frequency of syntactic structure affects priming, at least not for the comprehension of subject- and object-RCs. This is because, although the prime sentences used in Experiment 3 are high in type frequency by virtue of having an inanimate head noun (Kidd, et al., 2007; Mak, et al., 2002; Zubin, 1979), the effect could be instead attributable to introduction of an inanimate noun in general. Experiment 4 aimed to tease apart the effects of animacy distribution and prime type frequency.

\section{Experiment 4: Animacy disambiguation, low frequent type}

Experiment 4 primed participants with sentences such as (6), which contain an inanimate subject.

(6) Hier ist die Königin, die das Telefon weckt.

'Here is the queen ${ }_{[0 b j]}$ that the telephone ${ }_{[S u b j]}$ wakes'

As in the prime sentences in Experiment 3 (see example 5), the syntactic ambiguity in (6) is resolved by semantic cues. However, since the head noun is animate, sentence (6) has comparatively low type frequency for object RCs (Kidd, et al., 2007; Mak, Vonk \& Schriefers, 2002; Zubin, 1979). The frequency of the prime sentences used in Experiment 4 is therefore comparable to Experiments 1 and 2. 
However, in contrast to Experiment 1 and 2, Experiment 4 contains an animacy mismatch between primes and targets (all targets contained two animate NPs), as was the case in Experiment 3. Were it high type frequency of the prime sentences that led to the reduced priming in Experiment 3 compared to Experiments 1 and 2, then Experiment 4 should yield a priming effect similar to those observed in the first two experiments. If, however, priming was reduced in Experiment 4 because of the difference between animacy from the primes to the targets, we should also observe reduced priming in Experiment 4 similar to that observed in Experiment 3. That is, we should observe a phase*nativeness interaction, such that L2 speakers are primed to a greater extent than L1 speakers.

\section{Participants}

Twenty-four ( $N=24)$ new L1 Germans were tested, none of whom had participated in the earlier experiments. The mean age was 23 (range: $20-26$ ). Sixteen were female. Twenty-four $(N=24)$ new L2 Germans were tested. One L2 participant was replaced because of insufficient vocabulary knowledge. The final 24 L2 Germans made on average 13 mistakes in the vocabulary pre-test (min: 7, max: $20)$ and were 22 years old on average (min: 21, max: 23). None had studied any second language before the age of eight and the average time they had studied German was eight years (min: 3, max: 11). The L2 Germans had spent a mean of eight months in Germany or Austria (min: 4, max: 12 months). Fifteen were female.

\section{Materials}

The prime items of Experiment 1 were replaced by items with semantically disambiguated sentences that had an inanimate NP2 as the subject, as in example (6). The accompanying pictures again offered the only plausible object reading interpretation and an unrelated situation in the other picture. All other items were the same as in Experiment 1.

\section{Procedure}


The procedure was identical to that of Experiments 1 - 3.

Results

The data of Experiment 4 are displayed in Figure 6. As in Experiment 3, the L1 and L2 speakers responded differently over the course of the experiment. While OSV choices decreased slightly in the L1 speakers, the number rose from the baseline phase to the prime phase in the L2 speakers and remained stable over the post test.

\section{- INSERT FIGURE 6 ABOUT HERE -}

The analysis of Experiment 4 was carried out in to the same manner as those of the previous Experiments. The only meaningful random slope was phase in participant. Likelihood ratio tests showed that the full model fitted the data significantly better than the null model $\left(\chi^{2}(5)=55.60, p<.001\right)$, and that the interaction between prime phase and nativeness was significant $\left(\chi^{2}(2)=10.525, p\right.$ $=.005)$.

To investigate the pattern of the interaction in more detail the data were split by nativeness. As Figure 6 shows, the numbers of object readings slightly decreased across the three phases in the L1 speakers, indicating that there was no OSV priming. A likelihood ratio test between a model containing phase as a fixed factor and a null model without the fixed factor, both on the L1 data, showed that the full model fitted the data marginally better than the null model $\left(\chi^{2}(2)=5.14, p=.077\right)$, which indicates that there was a weak effect of phase within the L1 data. Next we analysed the location of this effect. The analysis showed that the small decrease of the numbers of ORs from the baseline phase to the prime phase was significant (estimate $=-1.17, \mathrm{SE}=0.45, \mathrm{z}=-2.48, p=0.01$ ). The decrease from the baseline phase to the post-test phase was also significant (estimate $=-0.74, \mathrm{SE}=0.39, \mathrm{z}=$ 1.96, $p=0.05$ ). This suggests that, as in Experiment 3, the prime items had little effect on the L1 speakers' interpretations of the target sentences; that is, the L1 
speakers pursued fewer ORs over the course of the experiment. This suggests that, as in Experiment 3, the L1 participants' preference for a SOV interpretation on test trials resulted in an 'anti-priming' effect, where their continued preference for the SOV over-rode any influence the prime items could have had.

For the L2 speakers the full model also fitted the data better than the null model $\left(\chi^{2}(2)=9.04, p=.01\right)$. The comparison between the baseline data and the prime phase data revealed a significant effect of OSV priming (estimate $=1.14, \mathrm{SE}=$ $0.35, z=3.26, p=0.001)$. The comparison between the prime phase and the posttest phase was also significant (estimate $=1.35, \mathrm{SE}=0.56, \mathrm{z}=2.41, p=0.02$ ), indicating that that the priming effect persisted over the post-test period. Because the interaction between phase and nativeness was significant, the model that best fits the data of Experiment 4 is the full model that includes all fixed (nativeness, phase) and random (participant, items) effects and the two-way interaction between the fixed effects (phase*nativeness), as shown in Table 4.

\section{- INSERT TABLE 4 ABOUT HERE -}

Experiment 4 aimed to tease apart the potential influence of type frequency and NP animacy on the priming of German OSV RCs, which were confounded in Experiment 3. The results were similar to those in Experiment 3: only the L2 speakers showed an effect of OSV priming, and the L1 speakers showed a significant increase of SOV mappings across the experiment. Since Experiments 3 and 4 differed only in the type frequency of the prime sentence, the results suggest that it was the animacy mismatch between prime and target sentences that resulted in the phase*nativeness interaction in the two experiments. However, there did also appear to be slight differences in the results. We next further scrutinised the Experiments 3 and 4 by directly comparing them in a new GLMM.

Since Experiment 3 and 4 contained significant interactions between phase and nativeness, it was not justified to investigate experiment* phase interactions across nativeness. We therefore had to carry out separate analyses for $L 1$ and $L 2$ speakers. 


\section{L1 between-experiment comparison of Experiment 3 and 4}

It was not possible to determine the meaningful random slopes nor to carry out any simplified GLMM on the pooled L1 data of Experiment 3 and 4 because of convergence errors. We therefore only comment qualitatively on the trends for this comparison.

\section{L2 between-experiment comparison of Experiment 3 and 4}

The meaningful random slopes were phase in participant and experiment in participant. The full model fitted the data better than the null model (likelihood ratio test: $\chi^{2}(5)=15.18, p=.01$ ), but the interaction between phase and experiment was not significant (likelihood ratio test: $\chi^{2}(2)=1.87, p=.39$ ).

Figure 7 shows the plotted data of Experiment 3 and 4 by nativeness. The figure shows that for the L2 data the phase*experiment interaction is not significant despite an initially stronger increase of OSV choices from the baseline to the prime phase. The figure also shows the data for the L1 data, for which the analysis could not be performed. The L1 data show a quite similar pattern in Experiment 3 and 4 . While no analysis can be performed, the close similarity between the L1 data of Experiment 3 and 4 suggest no interaction between phase ${ }^{*}$ nativeness.

\section{- INSERT FIGURE 7 ABOUT HERE -}

\section{Discussion}

Experiment 4 replicated the effect of nativeness on priming that was identified in Experiment 3. Again there was a significant interaction between nativeness and phase, which was due to the fact that there was no OSV priming in the L1 speakers, while OSV priming was found in the L2 speakers. This supports our hypothesis that nativeness can affect structural priming. As in Experiment 3, the L1 speakers of Experiment 4 showed a significant decrease in OSV mappings across the course of the experiment. Since the test items were ambiguous, this suggests that the L1 
speakers' preference for SOV mappings increased throughout the experiment, yielding an 'anti-priming' effect. In contrast, the L2 speakers were primed at levels equivalent to Experiments $1-3$. We interpret these results to indicate that $L 1$ speakers are less 'primeable' than L2 speakers and that that L1 and L2 speakers are differently susceptible to cues that cause a priming to emerge.

Experiments 3 and 4 differed in the type frequency of the primes but were similar in that they both had an animacy mis-match between prime and target. Since the results did not differ across the two experiments, we can conclude that type frequency within a constructional pattern does not have an appreciable effect on priming, but that animacy affects priming in a significant way. Bock et al. (1992) reported that animacy properties in the prime items were more likely to be reproduced in the target items than alternative animacy distributions. In Bock et al., actives with an inanimate subject such as The lightning struck the golfer were more likely to elicit targets that also contain inanimate subjects (e.g., The boat carried five people) than a target with an animate subject (e.g., Five people carried the boat). This result suggests that speakers prefer to map thematic roles from prime to target using animacy cues if available. This same preference may account for the absence of an effect of OSV priming in the L1 speakers in Experiments 3 and 4 . In contrast, the fact that the L2 speakers were still primed and showed no phase*experiment interactions offers some support for our original hypothesis that $L 2$ speakers show stronger priming than L1 speakers in designs where the prime effect can accumulate. We will discuss the role of animacy in more detail in the General Discussion.

That type frequency was found not to affect priming is inconsistent with earlier findings that the specific frequency of the prime structure also affects the outcome of priming (see Bock \& Loebell, 1990; Hartsuiker \& Kolk, 1998b; Hartsuiker, et al., 2004, Harsuiker \& Westenberg, 2000; Hartsuiker et al., 1999; Wells et al. 2009). However, the current research differs from previous in that it manipulated frequency within one single structural type. As such, this suggests a potential limit on frequency effects in priming. 


\section{General Discussion}

In the current paper we have presented four structural priming experiments in which prime items were systematically manipulated to investigate whether priming is influenced by a speaker's experience with the language (i.e., whether the participants are L1 or L2 speakers). Our hypothesis, drawing from experience-based approaches to language (Chang et al., 2006; MacDonald et al., 1994; Mitchell et al., 1995), was that L2 speakers should be more susceptible to priming than L1 speakers because they have less experience with the language.

Since the existence of a nativeness effect on priming in the past literature is unclear (e.g. Bernolet, et al., 2007; Nitschke et al., 2010; Schoonbaert, et al., 2007), we also hypothesized such an effect might be subtle, and only likely to be identified when the overall priming effect is weak. Therefore, to maximise the chance of identifying differences between L1 and L2 speakers we chose a design in which L1 and L2 speakers were primed for one structure only. This allowed the effect of priming to accumulate over the course of the experiment. As a consequence, such a design also caused small differences between L1 and L2 speakers to accumulate and become identifiable. To test our hypothesis, we systematically manipulated the prime conditions to diminish the priming effect. It was predicted that there should be instances where L2 speakers should be primed in conditions where L1 speakers are not, and that these conditions should diverge from contexts in which priming has been shown in the literature to be robust. That is, we expected the effect of nativeness on priming to emerge when priming was weakened because of (i) lack of verb overlap, (ii) higher type frequency of the prime sentences, and (iii) animacy mismatches between prime and target. In the case of our particular design, we expected to find significant experimental phase*nativeness interactions. These were observed in Experiments 3 and 4, where the L2 group was primed, but where the L1 group exhibited an anti-priming effect. Thus our hypothesis was supported. The data therefore suggest that it was the mismatch in animacy between prime and target that led to the differences in priming between the two groups. Bock et al. (1992) showed that animacy influences speakers' tendency to persist in assigning thematic roles across prime and target. As such, we can conclude that, in comparison to L1 speakers, less experienced L2 speakers persist in their thematic role assignment 
across prime and target despite differences that alter the priming effect in L1 speakers. This suggests that L2 speakers cast a wider "linguistic net" than do L1 speakers, where they more rigidly map thematic roles across prime-target pairs.

The present data raise a number of specific issues. The first concerns the extent to which priming is affected by experience, and what this means for models of language processing. Although some previous studies have shown that verb alternation biases predict priming effects (Bernolet \& Hartsuiker, 2010; Jaeger \& Snider, 2007), no previous studies have observed robust differences in groups of speakers that differ in their accumulated amount of linguistic experience. We have argued that previous studies did not observe experience-based nativeness effects because the effect is only likely to be observed in instances where the priming effect is weak enough as to be significantly diminished or absent in highly experienced language users (e.g., L1 adults), but detectable in the less experienced (e.g., L2 adults). Insofar as our results supported this hypothesis, the data are consistent with experience-based accounts of language processing, and the argument that syntactic priming represents a form of implicit learning of grammatical structure that accrues over the developmental history of a speaker (Chang, 2002; Chang et al., 2000; Chang et al., 2006). Were priming in the present studies due to effects of activation it would be difficult to explain why L2 speakers are primed more easily. However, priming was stronger in the L2 speakers. Similar results were reported by Nitschke et al. (2010) in a comparison of L1 and L2 speakers of Italian. The basic suggestion is that less experienced speakers are more likely to be primed because their linguistic system is more malleable and affected by experience. The data can be explained by appealing to implicit learning whereby linguistic knowledge is updated as a result of experience through backpropagation of error, as argued by Chang et al. (2006).

Although the data suggest that the L1 and L2 speakers were differentially primed and that therefore priming is affected by a speaker's experience with a language, our original proposal that this would be related to the entrenchment of structure does not seem to fit the data. Traditionally entrenchment is an argument about the degree to which a structural pattern instantiates a meaning in the mind of a speaker (e.g., active as instantiating a transitive event in comparison to a passive), a process that is driven by the frequency with which a structure occurs in the input. 
The results from Experiments 3 and 4 did not find type frequency to affect priming to any appreciable degree. As such, although structural priming effects appear to be affected by the frequency of competing syntactic structures (e.g. Ferreira \& Bock, 2006; Hartsuiker \& Kolk, 1998a; Hartsuiker \& Westenberg, 2000; MacDonald \& Christiansen, 2002; e.g. MacDonald, Pearlmutter \& Seidenberg, 1994; Scheepers, 2003; Seidenberg, 1985; Wells, et al., 2009), intra-constructional frequency manipulations appear have comparatively less influence.

The pattern of the data instead point to a role for similarity in priming that differs across native and non-native speaker groups. Snider (2009) has recently argued that similarity between prime and target drives priming, such that the magnitude of priming is directly proportional to the overlap between prime and target. In two analyses of naturalistic speech from the Switchboard Corpus (Marcus, Santorini, \& Marcinkiewicz, 1994), Snider showed that the degree of similarity between prime and target, as measured by a formal similarity metric that calculated distance between structures based on features such as inanimate recipient and plural theme, predicted the choice of ditransitive construction use. These data were interpreted to suggest that the general notion of similarity affects structural priming. This explanation accounts for lexical boost effects reported in previous studies (e.g., Cleland \& Pickering, 2003; Pickering \& Branigan, 1998). Interpreted in this manner, the lack of priming in L1 in Experiments 3 and 4 can be attributed to dissimilarity between prime and target; the animacy mismatch was enough to prevent L1 participants from pursuing the dispreferred OSV reading of the target sentence. The consistent priming effects observed in the L2 group suggests that this group is insensitive to manipulations of animacy, and as such calculate similarity differently to more experienced speakers. Instead, it appears that the order of thematic roles in ambiguous NNV structures was primeable irrespective of the animacy properties of nouns.

Successful comprehension involves the correct mapping of NPs to argument roles, and proficient L1 speakers develop strong expectancies about such mappings. For instance, Gennari and MacDonald (2008) showed that adult English L1 speakers' thematic role assignment in OSV RCs differed according to the animacy of the head noun. When the head noun is inanimate they were more likely to pursue an 
OSV RC interpretation, suggesting that semantic cues such as animacy modulate structural selection in proficient L1 speakers (see also Bornkessel-Schlesewsky \& Schlesewsky, 2009; Mak et al., 2002). Such preferences are likely to develop during acquisition; for instance, Brandt et al. (2009) have shown similar sensitivity to animacy cues in 3-year-old English and German-speaking children. If such formfunction correlations are learned and strengthened over the course of acquiring a language (Bates \& MacWhinney, 1989; Chang, 2002; Chang et al., 2006; MacDonald et al., 1994), then speakers who have different levels of exposure to a language will differ in the strength with which they are sensitive to cues such as animacy. Therefore, we suggest that the insensitivity of the L2 speakers to NP animacy across prime-target pairs ultimately reflects an experience-dependent effect.

Consequently, what we appear to be observing in the L1 and L2 groups are differential weightings applied to cues to interpretation across prime-target pairs. Whereas the L1 groups required both a semantic and a surface structure match across prime-target pairs to pursue the same interpretation, the L2 groups required only the same surface structure, ignoring NP semantics. We consider two questions arising from this result. Firstly, why does being a less experienced L2 speaker of a language lead to a greater persistence in mapping NP sentence position to argument roles? Secondly, is there an explanation according to which such a persistence would bring benefits for the acquisition and use of language?

Consistently mapping NP sentence position to argument roles may be a useful language learning strategy, for a number of reasons. Firstly, languages provide a number of cues that constrain interpretation, one of which is word order (see Bates \& MacWhinney, 1989). Speakers will be differentially sensitive to such cues depending on their availability and their reliability in a given language. Our L2 speakers all had English as their L1, a language that relies on word order to mark thematic roles; therefore part of what we are observing may be transfer of language processing strategies from $L 1$ to $L 2^{3}$. At the same time, less experienced language users are also likely to experience a processing bottleneck, leading to an inability to coordinate all cues to comprehension that may exist in the language. In such

\footnotetext{
${ }^{3}$ This differs from transfer of structure, which we address below.
} 
circumstances, it is useful to persist in the use of comprehension strategies that have been successful in the past. Since our prime trials only provided an OSV reading of prime sentence, the participants were assured of correctly interpreting the sentence. This then led to the persistent use of the same interpretive strategy in the test trial. A number of additional issues require discussion. The present data contrast with results reported by Carminati et al. (2008), who did not find animacy to affect priming in the comprehension of double object (DO) and prepositional object (PO) datives. The difference in results is likely to be attributable to the different structures used across the experiments. Our research and that of Bock et al. used structures where the animacy of core arguments was manipulated. In these transitive structures animacy is not rigidly associated with any given thematic role (although there are statistical tendencies). In contrast, the dative constructions are two constructions where the animacy of the object and indirect object are in complementary distribution. In general, the recipient argument is animate, whereas the theme argument is most often inanimate. Therefore, we suggest that Carminati et al.'s finding is attributable to the constructions they tested, which rigidly map animacy properties to NP positions and hence thematic roles. However, we also point out that Snider (2009) found animacy to affect priming in naturalistic speech. This suggests that the effect that similarity might have on priming may differ across comprehension and production as well as between different structures.

Another feature of our data suggests that similarity might be computed differently for different structures. Open-class lexical overlap between primes and targets has been found in general to boost priming effects. With respect to comprehension, priming effects have been argued to be dependent on open-class overlap (Arai, et al., 2007; Branigan, et al., 2005; Cleland \& Pickering, 2006; Corley \& Scheepers, 2002; Pickering \& Branigan, 1998). The present data are not consistent with these results. In Experiment 1 priming persisted over a phase without further prime administration despite the lack of open-class lexical overlap, and magnitude of the priming was comparable to that observed by Nitschke et al. (2010), who primed the same construction with verb overlap. This finding contrasts with studies that have reported no priming in comprehension in the absence of openclass lexical overlap (e.g. Arai, et al., 2007; Branigan, et al., 2005). For example, Branigan et al. (2005) primed English-speaking participants using sentences that 
contained ambiguity of prepositional phrase (PP) attachment, as in the sentence The clown pokes the man with the banana, where the ambiguous PP with the banana can modify either the verb or the second NP the man. Arai et al. (2007) primed participants in an on-line study for DO or PO datives, and only found priming when there was verb overlap between prime and target (e.g. The pirate will send the princess the necklace/The pirate will send the necklace to the princess). This difference may be due to the centrality of the verb in PP-attachment and ditransitives, on the one hand, and the backgrounded nature of the verb in German RCs on the other. Ambiguous V-NP-PP structures have been shown to be affected by verb type (Snedeker \& Trueswell, 2004; Spivey-Knowlton \& Sedivy, 1995). The same is true for PO and DO datives (Goldberg, 1995). Unlike these two structures, RCs are less likely to be subject to verb bias (but see Gennari \& MacDonald, 2008). This may be because in German NNV RCs the main verb is sentence-final, and is therefore not likely to be as informative to a left-to-right parser as in constructions where the verb is sentence-initial or medial.

A further difference between the current set of studies and the Arai et al. (2007) and Branigan et al. (2005) is that we primed participants for one syntactic structure only (i.e. object RCs). Priming possibly reinforces through repetition when one type of structure is primed (see Hartsuiker \& Westenberg, 2000; Kaschak, 2007; Kaschak, et al., 2006), which could be the reason why the present studies observed priming to be unaffected by the lack of open-class lexical overlap.

Finally, we address one potential methodological objection to our data. It could be argued that priming in the $\mathrm{L} 2$ participants was stronger than priming in the $L 1$ participants because of $L 1$ transfer. This is because all of our $L 2$ participants had English as their L1, and in English NNV RCs are only OSV, but not SOV. This may have allowed a direct mapping between the English and German forms. We argue that this contingency does not affect our conclusions about the (i) effect of nativeness and (ii) the effect of animacy on priming. Firstly, Nitschke et al. (2010) showed that speakers of L2 Italian showed a similar effect despite the fact the same mapping does not exist from their L1 English to Italian (i.e., transfer is not possible). Furthermore, if $L 1$ transfer affected the outcome in our experiments then it should have affected the results in all four experiments. However, the $\mathrm{L} 2$ speakers showed 
some sensitivity to the manipulation of animacy, as shown by the interaction between Experiments 1 and 3. As such, even if L1 transfer did influence our data, the phenomenon could not explain the full range of results.

\section{Conclusion}

The present paper investigated whether L2 speakers are more susceptible to priming than L1 speakers. The findings support this hypothesis. A likely explanation for the higher susceptibility to priming in L2 speakers than in L1 speakers is that L2 processing mechanisms are more malleable than $\mathrm{L} 1$ processing mechanisms. This is because speakers have less experience with their L2 compared to their L1. Such an account fits learning theories that take into account the quantity of exposure to linguistic structure (Chang, et al., 2006; Hernández, Li \& MacWhinney, 2005; Hulstijn, 2002; Mitchell, 1994). Therefore, the effect of nativeness supports an account of language where structures become entrenched in the minds of speakers over time through increased use (e.g., Chang et al., 2006). Increased exposure to a structure increases the likelihood that it will be used again because each exposure strengthens the link between form and meaning. A speaker's total experience with the language therefore indicates the degree to which a given structure will be entrenched, and therefore the degree to which that same structure can be affected by priming. Our L2 participants were primed in Experiments 3 and 4 despite the fact that the primes were fairly dissimilar from the targets, containing different verbs and different animacy configurations. The fact that the L2 participants were primed in a larger and broader set of linguistic contexts than were the L1s suggests that they cast a wider 'linguistic net' than native speakers, where they more rigidly map thematic roles across prime-target sequences. 
ACKNOWLEDGEMENTS: Participants for this study were tested at the following universities and we owe the named persons a debt of gratitude for providing testing space and advertising our research to L1 and L2 speakers: The University of Manchester, UK (Wiebke Brockhaus-Grand); Universität Erfurt, Germany (Gerhard Blanken, Tilmann Betsch, Margret Seyboth, Manuela Linde); The University of York, UK (Marilyn Vihman); Liverpool University, UK (Ulrike Bavendiek); The University of Lancaster, UK (Birgit Smith), The University of Bangor, UK (Susanne Schiemenz); Friedrich Schiller Universität, Germany (Holger Diessel); Australian National University, Canberra, Australia (Louise Jansen); The University of Salford, UK (Juliet Wigmore, Charlotte Hofmann). 


\section{REFERENCES}

Arai, M., van Gompel, R. P. G., \& Scheepers, C. (2007). Priming ditransitive structures in comprehension. Cognitive Psychology, 54(3), 218-250.

Abbot-Smith, K., Lieven, E., \& Tomasello, M. (2008) Graded representations in the acquisition of English and German transitive constructions. Cognitive Development, $23,48-66$

Baayen, R. H., Davidson, D. J., \& Bates, D. M. (2008). Mixed-effects modeling with crossed random effects for subjects and items. Journal of Memory and Language, 59(4), 390-412.

Bates, E. \& MacWhinney, B. (1989). Functionalism and the competition model. In: B. MacWhinney \& E. Bates (eds), The crosslinguistic study of sentence processing. Cambridge: CUP.

Bates, D., \& Maechler, M. (2010). Ime4: Linear mixed-effects models using S4 classes. R package version 0.999375-33.

Bernolet, S., \& Hartsuiker, R. (2010). Does verb bias modulate syntactic priming? Cognition, 114(3), 455-461.

Bernolet, S., Hartsuiker, R. J., \& Pickering, M. J. (2007). Shared syntactic representations in bilinguals: Evidence for the role of word-order repetition. Journal of Experimental Psychology: Learning, Memory, and Cognition, 33(5), 931-949.

Bernolet, S., Hartsuiker, R. J., \& Pickering, M. J. (2009). Persistence of emphasis in language production: A cross-linguistic approach. Cognition, 112(2), 300-317.

Bock, J. K. (1986). Syntactic persistence in language production. Cognitive Psychology, 18(3), 355-387.

Bock, K., Dell, G. S., Chang, F., \& Onishi, K. H. (2007). Persistent structural priming from language comprehension to language production. Cognition, 104(3), 437-458.

Bock, K., \& Griffin, Z. M. (2000). The persistence of structural priming: transient activation or implicit learning? Journal of Experimental Psychology: General, 129(2), 177-192.

Bock, K., \& Loebell, H. (1990). Framing sentences. Cognition, 35(1), 1-39.

Bock, K., Loebell, H., \& Morey, R. (1992). From conceptual roles to structural relations: Bridging the syntactic cleft. Psychological Review, 99(1), 150-171.

Bornkessel-Schlesewsky, I. \& Schlesewsky, M. (2009). The role of prominence information in the real time comprehension of transitive constructions: A cross-linguistic approach. Language and Linguistics Compass, 3, 19-58.

Brandt, S., Kidd, E., Lieven, E., \& Tomasello, M. (2009). The discourse bases of relativization: An investigation of young German and English-speaking 
children's comprehension of relative clauses. Cognitive Linguistics, 20, 539 570.

Branigan, H. (2006). Syntactic priming. Language and Linguistics Compass, 1, 2-16.

Branigan, H. P., Pickering, M. J., \& Cleland, A. A. (2000a). Syntactic co-ordination in dialogue. Cognition, 75(2), B13-25.

Branigan, H. P., Pickering, M. J., \& McLean, J. F. (2005). Priming prepositionalphrase attachment during comprehension. Journal of Experimental Psychology: Learning, Memory, and Cognition, 31(3), 468-481.

Branigan, H. P., Pickering, M. J., Stewart, A. J., \& McLean, J. F. (2000b). Syntactic priming in spoken production: linguistic and temporal interference. Memory \& Cognition, 28(8), 1297-1302.

Carminati, M. N., \& Van Gompel, R. P. G. (2009). Time course of structural priming in comprehension. Paper presented at the CUNY 2009.

Carminati, M. N., van Gompel, R. P. G., Scheepers, C., \& Arai, M. (2008). Syntactic Priming in Comprehension: The Role of Argument Order and Animacy. Journal of Experimental Psychology: Learning, Memory, and Cognition, 34(5), 1098-1110.

Carroll, S., \& Swain, M. (1993). Explicit and Implicit Negative Feedback: An Empirical Study of the Learning of Linguistic Generalizations. Studies in Second Language Acquisition, 15(3), 357-386.

Chang, F. (2002). Symbolically speaking: A connectionist model of sentence production. Cognitive Science, 26, 609-651.

Chang, F., Dell, G. S., \& Bock, K. (2006). Becoming syntactic. Psychological Review, 113(2), 234-272.

Chang, F., Dell, G. S., Bock, K., \& Griffin, Z. M. (2000). Structural priming as implicit learning: a comparison of models of sentence production. Journal of Psycholinguistic Research, 29(2), 217-229.

Chang, F., Kobayashi, T. and Amano, S. (2009). Social factors in the acquisition of a new word order. First Language 29(4), 427-445.

Clahsen, H., \& Felser, C. (2006a). Continuity and shallow structures in language processing. Applied Psycholinguistics, 27(1), 107-126.

Clahsen, H., \& Felser, C. (2006b). Grammatical processing in language learners. Applied Psycholinguistics, 27(1), 3-42.

Clahsen, H., \& Felser, C. (2006c). How native-like is non-native language processing? Trends in Cognitive Sciences, 10(12), 564-570.

Clark, H. H. (1973). The language-as-fixed-effect fallacy: A critique of language statistics in psychological research. Journal of Verbal Learning and Verbal Behavior, 12(4), 335-359.

Cleland, A. A., \& Pickering, M. J. (2006). Do writing and speaking employ the same syntactic representations? Journal of Memory and Language, 54(2), 185-198. 
Corley, M., \& Scheepers, C. (2002). Syntactic priming in English sentence production: categorical and latency evidence from an Internet-based study. Psychonomic Bulletin \& Review, 9(1), 126-131.

Cuetos, F., Mitchell, D. C., \& Corley, M. M. B. (1996). Parsing in different languages. In M. Carreiras, J. E. García-Albea \& N. Sebastián-Gallés (Eds.), Language processing in Spanish. Mahwah, New Jersey: Lawrence Erlbaum Associates.

Ellis, N. C., \& Schmidt, R. (1998). Rules or Associations in the Acquisition of Morphology? The Frequency by Regularity Interaction in Human and PDP Learning of Morphosyntax. Language and Cognitive Processes, 13(2), 307 336.

Ferreira, V. S., \& Bock, K. (2006). The functions of structural priming. Language and Cognitive Processes, 21(7), 1011 - 1029.

Ferreira, V. S., Bock, K., Wilson, M. P., \& Cohen, N. J. (2008). Memory for Syntax Despite Amnesia. Psychological Science, 19(9), 940-946.

Fox, B. A., \& Thompson, S. A. (1990). A Discourse Explanation of the Grammar of Relative Clauses in English Conversation. Language, 66(2), 297-316.

Fox, B. A., \& Thompson, S. A. (2007). Relative Clauses in English conversation: Relativizers, frequency, and the notion of construction. Studies in Language, 31, 293-326.

Ferreira, V. S., \& Bock, K. (2006). The functions of structural priming. Language and Cognitive Processes, 21(7), 1011 - 1029.

Ferreira, V. S., Bock, K., Wilson, M. P., \& Cohen, N. J. (2008). Memory for Syntax Despite Amnesia. Psychological Science, 19(9), 940-946.

Gennari, S. P., \& MacDonald, M. C. (2008). Semantic indeterminacy in object relative clauses. Journal of Memory and Language, 58(2), 161-187.

Goldberg, A. E. (1995). A construction grammar approach to argument structure. Chicago: The University of Chicago Press.

Graf, P., Squire, L. R., \& Mandler, G. (1984). The information that amnesic patients do not forget. Journal of Experimental Psychology: Learning, Memory, and Cognition, 10(1), 164-178.

Hartsuiker, R. J., Bernolet, S., Schoonbaert, S., Speybroeck, S., \& Vanderelst, D. (2008). Syntactic priming persists while the lexical boost decays: Evidence from written and spoken dialogue. Journal of Memory and Language, 58(2), 214-238.

Hartsuiker, R. J., \& Kolk, H. H. J. (1998a). Syntactic facilitation in agrammatic sentence production. Brain and Language, 62, 221-254.

Hartsuiker, R. J., \& Kolk, H. H. J. (1998b). Syntactic persistence in Dutch. Language and Speech, 41(2), 143-184.

Hartsuiker, R. J., Kolk, H. H. J., \& Huiskamp, P. (1999). Priming word order in sentence production. Quarterly Journal of Experimental Psychology, 52A(1), 129-147. 
Hartsuiker, R. J., Pickering, M. J., \& Veltkamp, E. (2004). Is syntax separate or shared between languages? Cross-linguistic syntactic priming in spanishenglish bilinguals. Psychological Science, 15(6), 409-414.

Hartsuiker, R. J., \& Westenberg, C. (2000). Word order priming in written and spoken sentence production. Cognition, 75(2), B27-B39.

Hernández, A., Li, P., \& MacWhinney, B. (2005). The emergence of competing modules in bilingualism. Trends in Cognitive Sciences, 9(5), 220-225.

Huettig, F., \& Altmann, G. T. M. (2004). The on-line processing of ambiguous and unambiguous words in context: evidence from head mounted eyetracking. In M. Carreiras \& J. Charles Clifton (Eds.), The On-line Study of Sentence Comprehension. Eyetracking, ERPs and Beyond. New York: Psychology Press.

Hulstijn, J. (2002). Towards a unified account of the representation, processing and acquisition of second language knowledge. Second Language Research, 18(3), 193-223.

Jaeger, T. F. (2008). Categorical data analysis: Away from ANOVAs (transformation or not) and towards logit mixed models. Journal of Memory and Language, 59(4), 434-446.

Jaeger, T. F., \& Snider, N. (2007). Implicit learning and syntactic persistence: Surprisal and cumulativity. In L. Wolter \& J. Thorson (Eds.), University of Rochester Working Papers in the Language Sciences (Vol. 3(1), pp. 26-44).

Kaiser, E., \& Trueswell, J. C. (2004). The role of discourse context in the processing of a flexible word-order language. Cognition, 94(2), 113-147.

Kamide, Y., \& Mitchell, D. C. (1999). Incremental Pre-head Attachment in Japanese Parsing. Language and Cognitive Processes, 14(5), 631 - 662.

Kamide, Y., Scheepers, C., \& Altmann, G. T. M. (2003). Integration of Syntactic and Semantic Information in Predictive Processing: Cross-Linguistic Evidence from German and English. Journal of Psycholinguistic Research, 32(1), 37-55.

Kaschak, M. P. (2007). Long-term structural priming affects subsequent patterns of language production. Memory \& Cognition, 35(5), 925-937.

Kaschak, M. P., Loney, R. A., \& Borreggine, K. L. (2006). Recent experience affects the strength of structural priming. Cognition, 99(3), B73-B82.

Kidd, E. (in press). Implicit statistical learning is directly associated with the acquisition of syntax. Developmental Psychology. doi: 10.1037/a0025405.

Kidd, E., Brandt, S., Lieven, E., \& Tomasello, M. (2007). Object relatives made easy: A cross-linguistic comparison of the constraints influencing young children's processing of relative clauses. Language and Cognitive Processes, 22(6), 860 - 897.

Knoeferle, P., Crocker, M. W., Scheepers, C., \& Pickering, M. J. (2005). The influence of the immediate visual context on incremental thematic roleassignment: evidence from eye-movements in depicted events. Cognition, 95(1), 95-127. 
Loebell, H., \& Bock, K. (2003). Structural priming across languages. Linguistics, 41(5), 791-824.

Logan, G. D. (1985). On the ability to inhibit simple thoughts and actions: II. StopSignal Studies of repetition priming. Journal of Experimental Psychology: Learning, Memory, \& Cognition October, 11(4), 675-691.

MacDonald, M. C., \& Christiansen, M. H. (2002). Reassessing Working Memory: Comment on Just and Carpenter (1992) and Waters and Caplan (1996). Psychological Review January, 109(1), 35-54.

MacDonald, M. C., Pearlmutter, N. J., \& Seidenberg, M. S. (1994). Lexical Nature of Syntactic Ambiguity Resolution. Psychological Review, 101(4), 676-703.

MacWhinney, B., James, J. S., Schunn, C., Li, P., \& Schneider, W. (2001). STEP-A system for teaching experimental psychology using E-Prime. Behavior Research Methods, Instruments, \& Computers, 33 (2), 287-296.

Mak, W. M., Vonk, W., \& Schriefers, H. (2002). The Influence of Animacy on Relative Clause Processing. Journal of Memory and Language, 47(1), 50-68.

Marcus, M. P., Santorini, B., \& Marcinkiewicz, M. A. (1994). Building a large annotated corpus of English: The Penn Treebank. Computational Linguistics, 19(2), 313-330.

McDonough, K. (2005). Identifying the impact of negative feedback and learners' responses on ESL question development. Studies in Second Language Acquisition, 27(01), 79-103.

McDonough, K. (2006). Interaction and syntactic priming: English L2 speakers' production of dative constructions. Studies in Second Language Acquisition, 28(02), 179-207.

Mitchell, D. C. (1994). Sentence parsing. In M. A. Gernsbacher (Ed.), Handbook of psycholinguistics (pp. 375-409). San Diego, CA: Academic Press.

Mitchell, D. C., Cuetos, F., Corley, M. M. B., \& Brysbaert, M. (1995). Exposure-based models of human parsing: Evidence for the use of coarse-grained (nonlexical) statistical records. Journal of Psycholinguistic Research, 24(6), 469-488.

Nicol, J. L., \& Pickering, M. J. (1993). Processing syntactically ambiguous sentences: Evidence from semantic priming. Journal of Psycholinguistic Research, V22(2), 207-237.

Nitschke, S., Kidd, E., \& Serratrice, L. (2010). First language transfer and long-term structural priming in comprehension. Language and Cognitive Processes, 25(1), 94-114.

Pickering, M. J., \& Branigan, H. P. (1998). The representation of verbs: evidence from syntactic priming in language production. Journal of Memory and Language, 39(4), 633-651.

Pickering, M. J., \& Ferreira, V. S. (2008). Structural priming: A critical review. Psychological Bulletin, 134(3), 427-459.

Prat-Sala, M., \& Branigan, H. P. (2000). Discourse constraints on syntactic processing in language production: A cross-linguistic study in English and Spanish. Journal of Memory and Language, 42, 168-182. 
Prat-Sala, M., Eacute, Shillcock, R., \& Sorace, A. (2000). Animacy effects on the production of object-dislocated descriptions by Catalan-speaking children. Journal of Child Language, 27(01), 97-117.

R Development Core Team (2009). R: A language and environment for statistical computing. R Foundation for Statistical Computing, Vienna, Austria.

Raffray, C. N., Pickering, M. J., \& Branigan, H. P. (2007). Priming the interpretation of noun-noun combinations. Journal of Memory and Language, 57(3), 380395.

Roelofs, A. (1992). A spreading-activation theory of lemma retrieval in speaking. Cognition, 42(1-3), 107-142.

Roland, D., Dick, F., \& Elman, J. L. (2007). Frequency of basic English grammatical structures: A corpus analysis. Journal of Memory and Language, 57, 348-379.

Salamoura, A., \& Williams, J. N. (2006). Lexical activation of cross-language syntactic priming. Bilingualism: Language and Cognition, 9(03), 299-307.

Salamoura, A., \& Williams, J. N. (2007). Processing verb argument structure across languages: Evidence for shared representations in the bilingual lexicon. Applied Psycholinguistics, 28(04), 627-660.

Scheepers, C. (2003). Syntactic priming of relative clause attachments: persistence of structural configuration in sentence production. Cognition, 89(3), 179-205.

Scheepers, C., \& Crocker, M. W. (2004). Constituent order priming from reading to listening: A visual-world study. In M. Carreiras \& C. Clifton Jr (Eds.), The online study of sentence comprehension: Eye-tracking, ERP and beyond (pp. 167-185). New York: Psychology Press.

Schoonbaert, S., Hartsuiker, R. J., \& Pickering, M. J. (2007). The representation of lexical and syntactic information in bilinguals: Evidence from syntactic priming. Journal of Memory and Language, 56(2), 153-171.

Seger, C. A. (1994). Implicit learning. Psychological Bulletin, 115(2), 163-196.

Seidenberg, M. S. (1985). The time course of phonological code activation in two writing systems. Cognition, 19(1), 1-30.

Shin, J-A., \& Christianson, K. (in press). Structural priming and second language learning. Language Learning. Doi: 10.1111/j.1467-9922.2011.00657.x

Snedeker, J., \& Trueswell, J. C. (2004). The developing constraints on parsing decisions: The role of lexical-biases and referential scenes in child and adult sentence processing. Cognitive Psychology, 49(3), 238-299.

Snider, N. (2008). An exemplar model of structural priming, PhD thesis. Stanford University, CA, Stanford.

Snider, N. (2009). Similarity and structural priming. In N. A. Taatgen \& H. van Rijn (Eds.), Proceedings of the 31st Annual Conference of the Cognitive Science Society (pp. 815 - 820). Austin, TX: Cognitive Science Society.

Spivey, M. J., Tanenhaus, M. K., Eberhard, K. M., \& Sedivy, J. C. (2002). Eye movements and spoken language comprehension: Effects of visual context on syntactic ambiguity resolution. Cognitive Psychology, 45(4), 447-481. 
Spivey-Knowlton, M., \& Sedivy, J. C. (1995). Resolving attachment ambiguities with multiple constraints. Cognition, 55(3), 227-267.

Thothathiri, M., \& Snedeker, J. (2008). Give and take: Syntactic priming during spoken language comprehension. Cognition, 108(1), 51-68.

Traxler, M. J., Morris, R. K., \& Seely, R. E. (2002). Processing Subject and Object Relative Clauses: Evidence from Eye Movements. Journal of Memory and Language, 47(1), 69-90.

Wells, J. B., Christiansen, M. H., Race, D. S., Acheson, D. J., \& MacDonald, M. C. (2009). Experience and sentence processing: Statistical learning and relative clause comprehension. Cognitive Psychology, 58(2), 250-271.

Zubin, D. A. (1979). Discourse function of morphology: The focus system in German. In T. Givón (Ed.), Syntax and Semantics: Discourse and Syntax (Vol. 12, pp. 469-504). New York: Academic Press.

\section{APPENDIX}

\section{Vocabulary of the pre-test: German/English}

Kellnerin/waitress,

Sängerin/singer (f)

Fotografin/photographer (f)

Krankenschwester/nurse (f)

Räuber/robber (m)

Großmutter/grandmother

Malerin/painter (f)

Polizist/police man

Königin/queen

Hexe/witch

Koch/chef $(\mathrm{m})$

Nonne/nun

Tennisspielerin/tennis player ( $f$ )

Violinistin/violinist (f)

Stock/stick

Fernglas/binoculars 
Hut/hat

Karotte/carrot

Kegel/cone

Blume/flower

Leine/leash

Schläger/racquet

Sonnenbrille/sun glasses

Regenschirm/umbrella

Pistole/gun

Lineal/ruler

Schal/scarf

Spritze/syringe

Bürste/brush

Röhre/tube

umarmen/to hug

suchen/to search

rufen/to call

schlagen/to hit

kratzen/to scratch

wählen/to chose

verfolgen/to follow

beschimpfen/to insult

bedrohen/to threaten

kämmen/to comb

kneifen/to pinch

grüßen/to wave

erschrecken/to scare

schubsen/to shove

bespritzen/to splash

strangulieren/to strangle

wecken/to wake

berühren/to touch

sehen/to see 
Nativeness in structural priming in comprehension

halten /to hold 


\section{FIGURES}

\section{PRIME TRIAL}

Hier ist die Krankenschwester, die die Ballerina umarmt.

'Here is the nurse [Sub/obj] $_{\text {th }}$ that the ballerina $a_{\text {[obj/Sub] }}$ hugs'
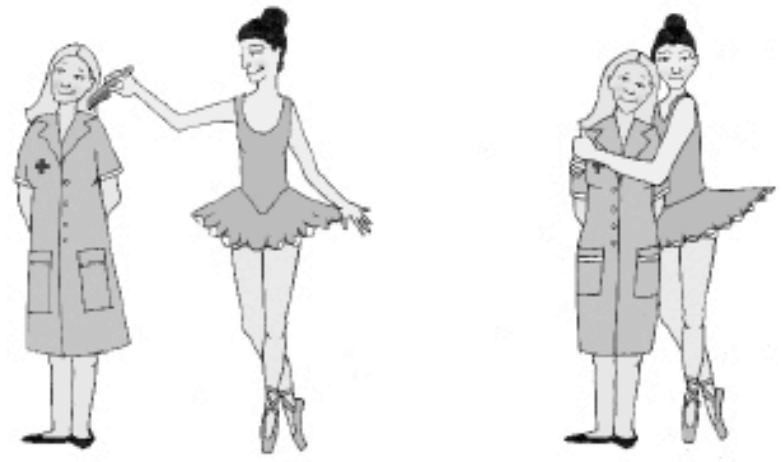

\section{TARGET TRIAL}

Hier ist die Sängerin, die das Kind grüßt.

'Here is the singer ${ }_{[S u b / o b j]}$ that the child ${ }_{[o b j / S u b]}$ greets'
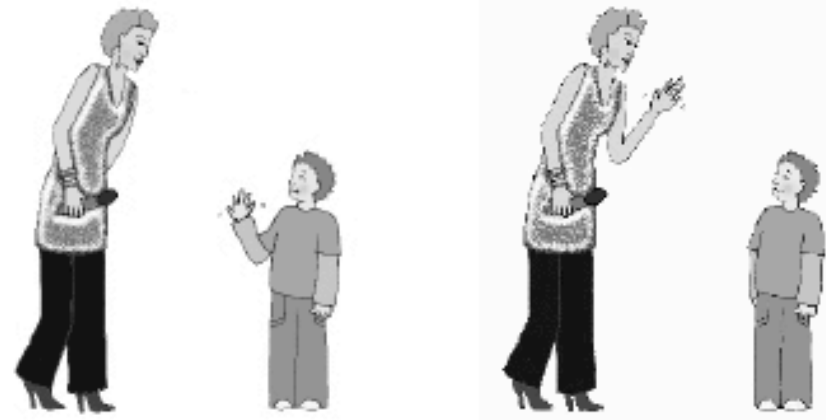

Figure 1: Example for items of prime trial (top) and target trial (bottom) 


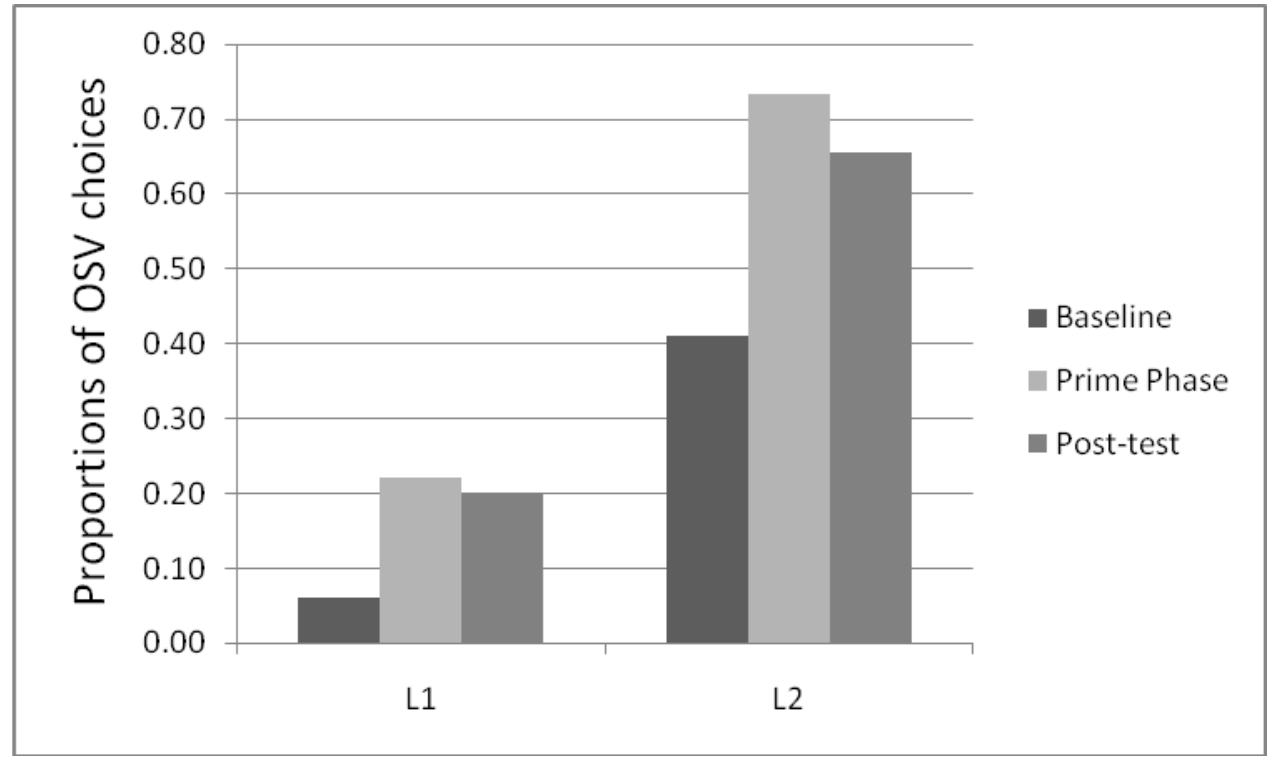

Figure 2: Proportions of object reading choices over the three phases of Experiment 1.

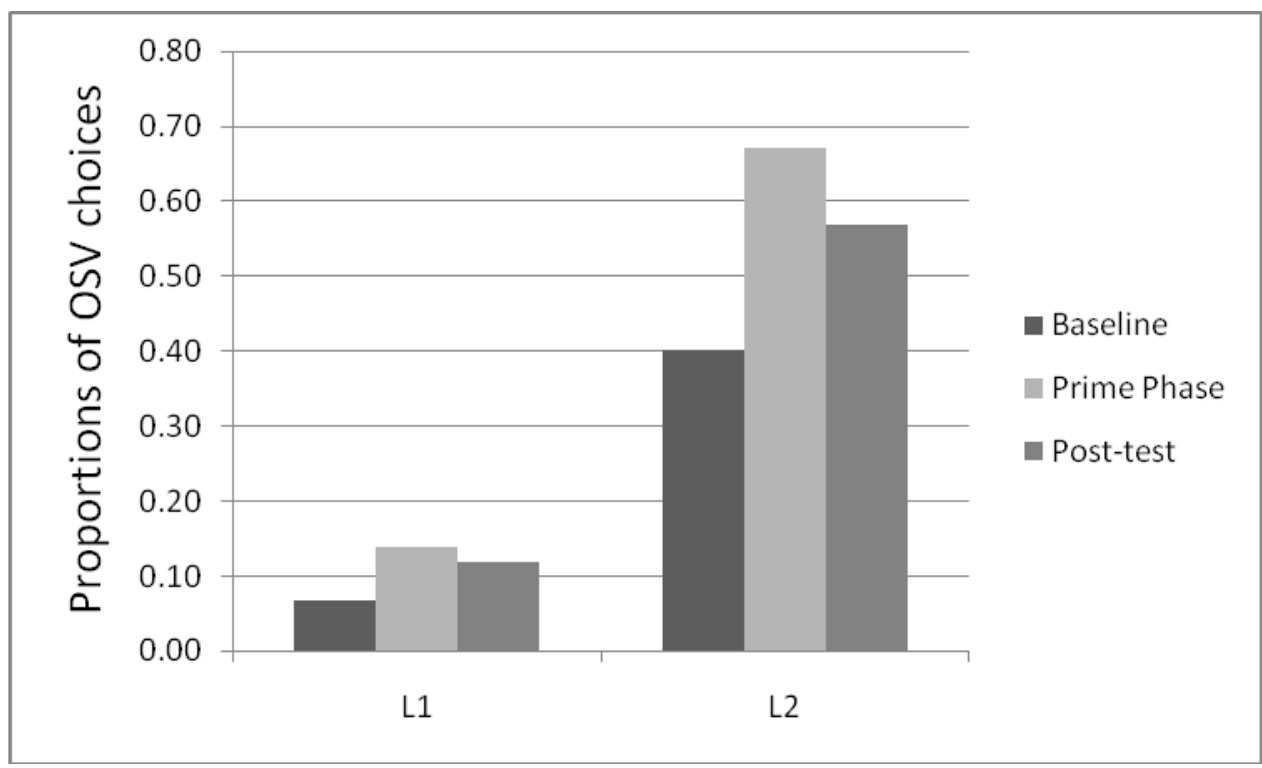

Figure 3: Proportions of object reading choices over the three phases of Experiment 2. 


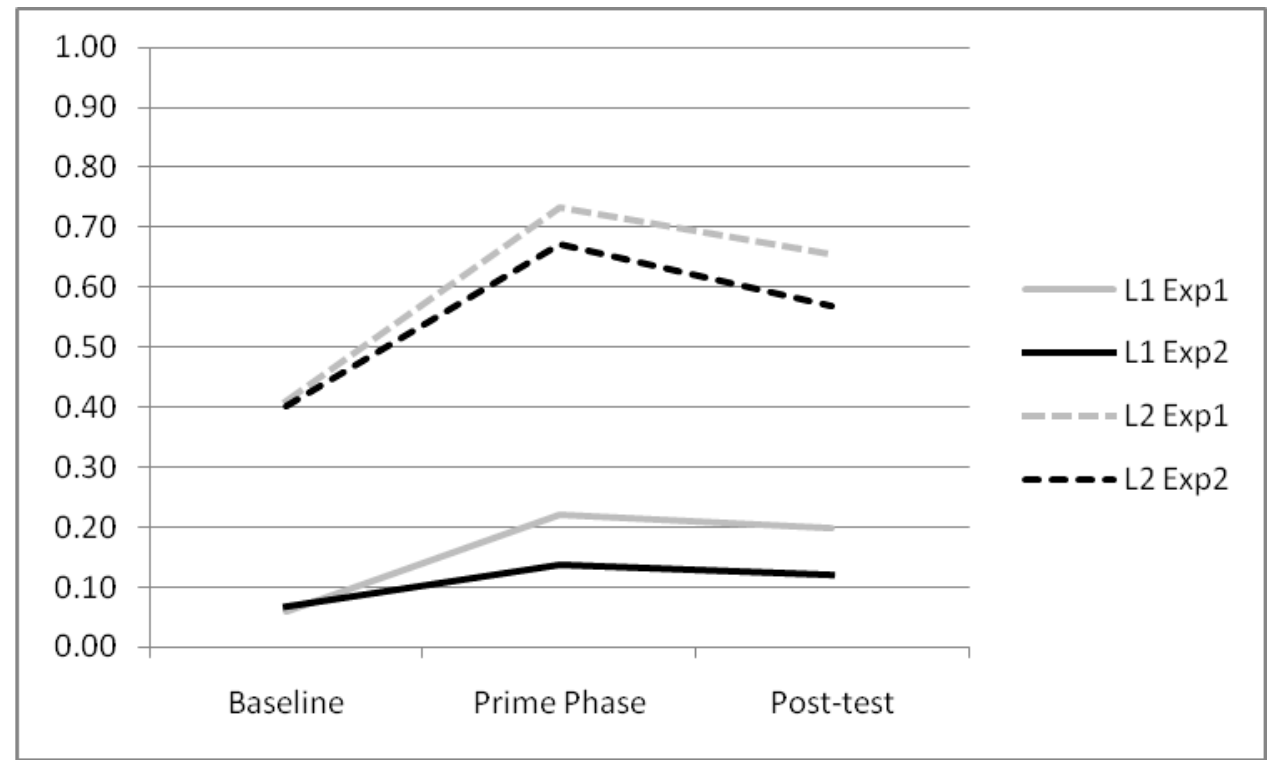

Figure 4: The phase ${ }^{*}$ experiment interaction of Experiment 1 and 2. All three way and two-way interactions were n.s. (all ps $>.20$ ).

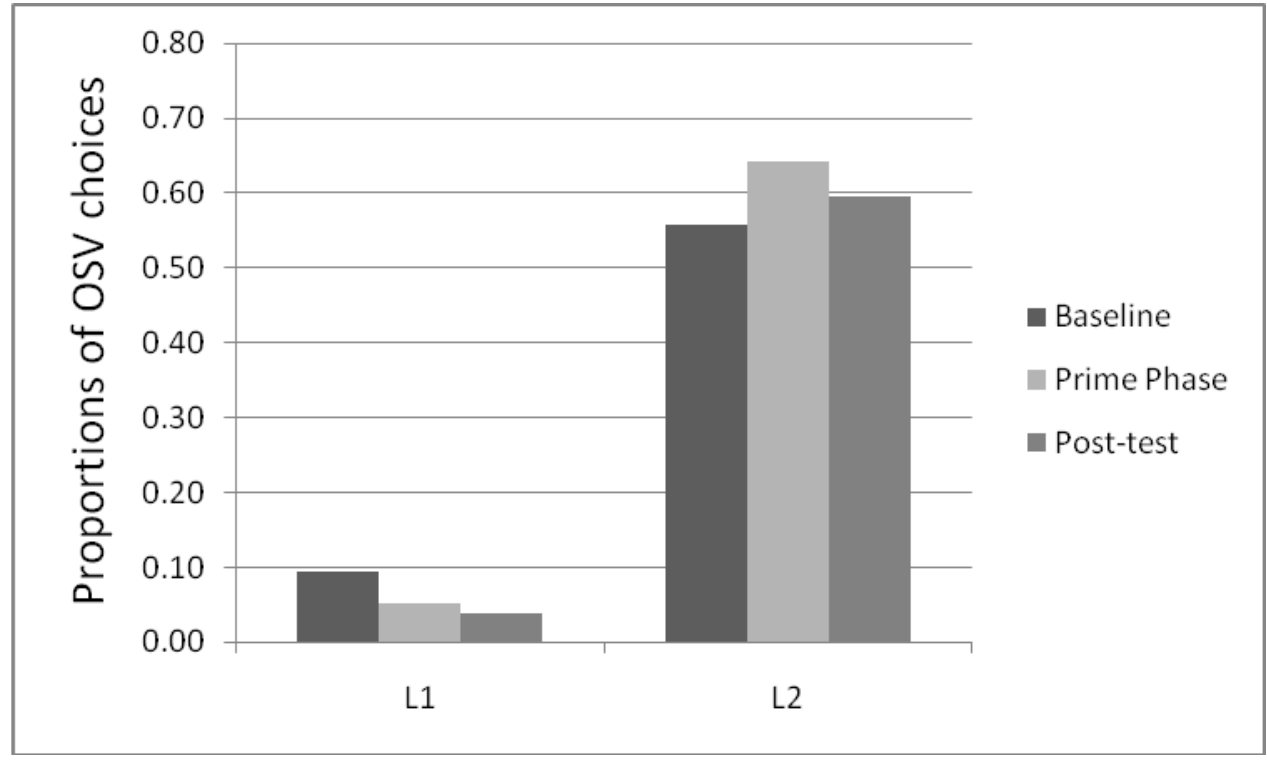

Figure 5: Proportions of object reading choices over the three phases of Experiment 3. 


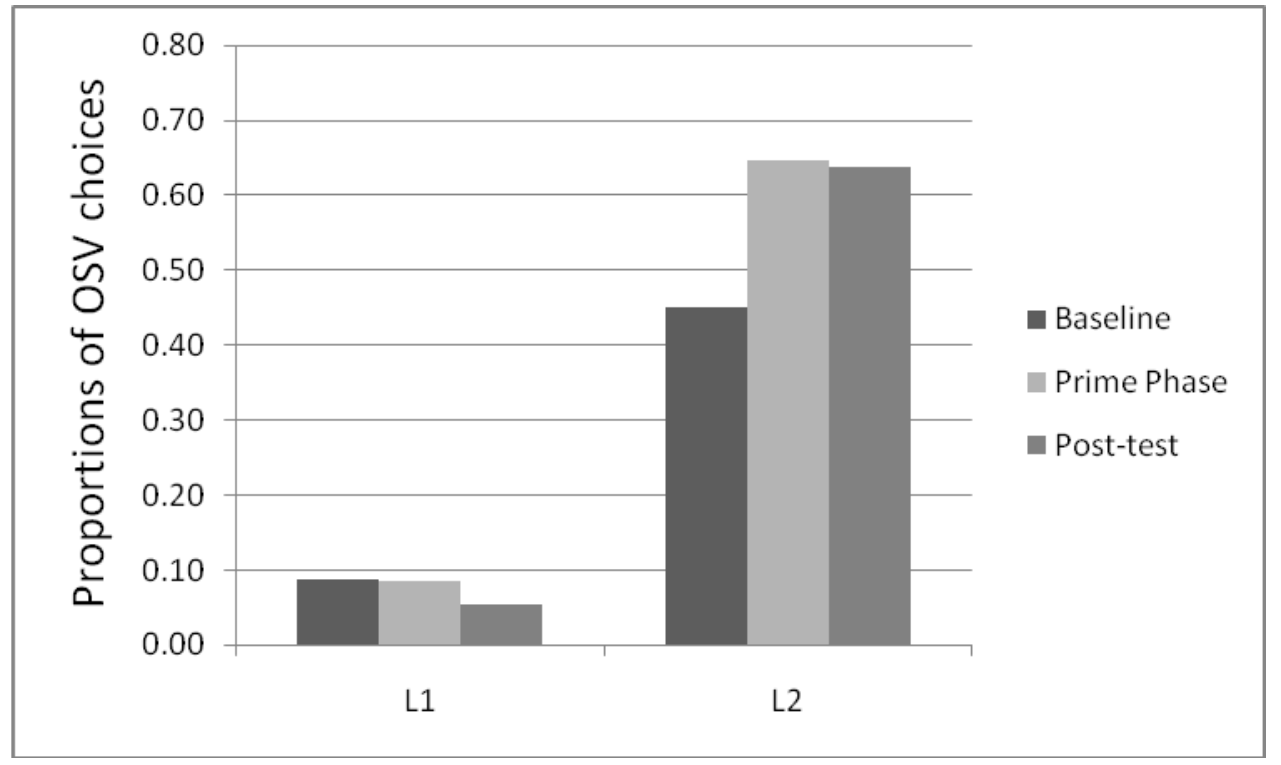

Figure 6: Proportions of object reading choices over the three phases of Experiment 4. 


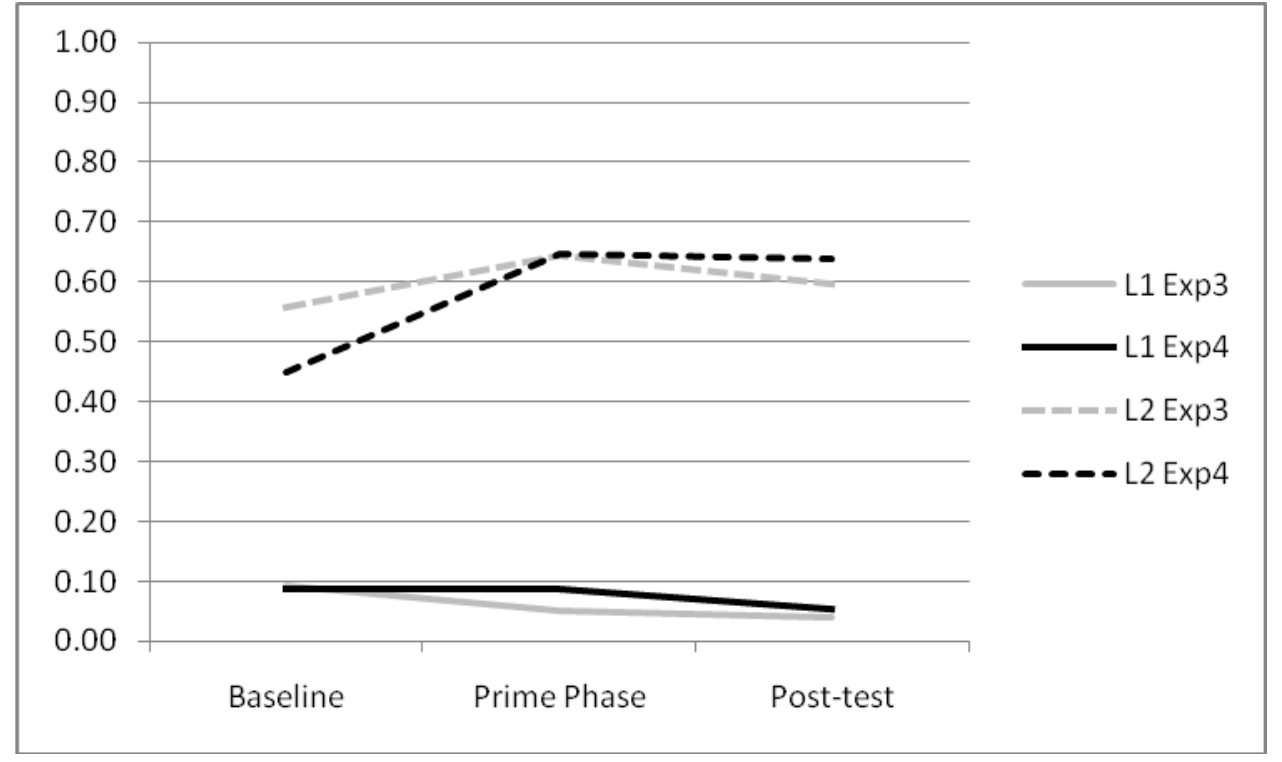

Figure 7: The phase ${ }^{*}$ experiment interaction of Experiment 3 and 4.

Significances: L1 Exp3*L1 Exp4: cannot be calculated; L2 Exp3*L2 Exp4: n.s.

\section{TABLES}

Table 1: Final model for the data of Experiment 1. The interaction has been removed because it was not significant.

\begin{tabular}{lllcl}
\hline Predictor & Estimate & $S E$ & $Z$ & $P$ \\
\hline (Intercept) & -3.53 & 0.35 & -10.22 & $<.001$ \\
Nativeness: L1 vs L2 & 3.03 & 0.38 & 7.88 & $<.001$ \\
Phase: Baseline vs Post-test & 1.25 & 0.42 & 2.99 & $=.003$ \\
Phase: Baseline vs Prime Phase & 1.72 & 0.35 & 4.89 & $<.001$ \\
\hline
\end{tabular}

Table 2: Final model for the data of Experiment 2. The interaction has been removed because it was not significant.

\begin{tabular}{lllll}
\hline Predictor & Estimate & $S E$ & $z$ & $P$ \\
\hline (Intercept) & -3.60 & 0.36 & -10.04 & $<.001$ \\
\hline
\end{tabular}




\begin{tabular}{lllll}
\hline Nativeness: L1 vs L2 & 3.07 & 0.37 & 8.42 & $<.001$ \\
Phase: Baseline vs Post-test & 0.92 & 0.35 & 2.65 & $=.008$ \\
Phase: Baseline vs Prime Phase & 1.44 & 0.30 & 4.78 & $<.001$ \\
\hline
\end{tabular}

Table 3: Full model of Experiment 3

\begin{tabular}{lllll}
\hline Predictor & Estimate & $S E$ & $Z$ & $p$ \\
\hline (Intercept) & -2.97 & 0.36 & -8.18 & $<.001$ \\
Nativeness: L1 vs L2 & 3.22 & 0.47 & 6.89 & $<.001$ \\
Phase: Baseline vs Post-test & -1.38 & 0.40 & -3.44 & $<.001$ \\
Phase: Baseline vs Prime Phase & -0.93 & 0.41 & -2.23 & $=.03$ \\
Interaction: & & & & \\
Nativeness(L1 vs L2) x Phase(Base vs Post) & 1.72 & 0.48 & 3.55 & $<.001$ \\
Nativeness(L1 vs L2) x Phase(Base vs Prime) & 1.71 & 0.51 & 3.36 & $<.001$ \\
\hline
\end{tabular}


Table 4: Full model of Experiment 4

\begin{tabular}{llccc}
\hline Predictor & Estimate & $S E$ & $Z$ & $P$ \\
\hline Intercept) & -2.77 & 0.31 & -9.02 & $<.001$ \\
Nativeness: L1 vs L2 & 2.50 & 0.40 & 6.32 & $<.001$ \\
Phase: Baseline vs Post-test & -1.05 & 0.54 & -1.92 & $=.06$ \\
Phase: Baseline vs Prime Phase & -0.56 & 0.43 & -1.30 & $=.19$ \\
Interaction: & & & & $=.002$ \\
Nativeness(L1 vs L2) x Phase(Base vs Post) & 2.22 & 0.70 & 3.17 & $=.001$ \\
Nativeness(L1 vs L2) x Phase(Base vs Prime) & 1.76 & 0.55 & 3.20 & \\
\hline
\end{tabular}

